Review

\title{
Synthesis of Silver Nanostructures by Multistep Methods
}

\section{Tong Zhang ${ }^{1,2, *}$, Yuan-Jun Song ${ }^{1,2,3}$, Xiao-Yang Zhang ${ }^{1,2}$ and Jing-Yuan $\mathrm{Wu}^{1,2}$}

1 School of Electronic Science and Engineering, Southeast University, and Key Laboratory of Micro-Inertial Instrument and Advanced Navigation Technology, Ministry of Education, Nanjing 210096, China; E-Mails: songyuanjunwf@163.com (Y.-J.S.); zxycom@163.com (X.-Y.Z.); wwjjyy92@163.com (J.-Y.W.)

2 Suzhou Key Laboratory of Metal Nano-Optoelectronic Technology, Suzhou Research Institute of Southeast University, Suzhou 215123, China

3 School of Chemistry and Chemical Engineering, Southeast University, Nanjing 211189, China

* Author to whom correspondence should be addressed; E-Mail: tzhang@ seu.edu.cn; Tel.: +86-25-8379-2449 (ext. 833); Fax: +86-25-8336-3222.

Received: 13 January 2014; in revised form: 16 March 2014 / Accepted: 18 March 2014 / Published: 25 March 2014

\begin{abstract}
The shape of plasmonic nanostructures such as silver and gold is vital to their physical and chemical properties and potential applications. Recently, preparation of complex nanostructures with rich function by chemical multistep methods is the hotspot of research. In this review we introduce three typical multistep methods to prepare silver nanostructures with well-controlled shapes, including the double reductant method, etching technique and construction of core-shell nanostructures. The growth mechanism of double the reductant method is that different favorable facets of silver nanocrystals are produced in different reductants, which can be used to prepare complex nanostructures such as nanoflags with ultranarrow resonant band bandwidth or some silver nanostructures which are difficult to prepare using other methods. The etching technique can selectively remove nanoparticles to achieve the aim of shape control and is widely used for the synthesis of nanoflowers and hollow nanostructures. Construction of core-shell nanostructures is another tool to control shape and size. The three methods can not only prepare various silver nanostructures with well-controlled shapes, which exhibit unique optical properties, such as strong surface-enhanced Raman scattering (SERS) signal and localized surface plasmon resonance (LSPR) effect, but also have potential application in many areas.
\end{abstract}


Keywords: reductant; nanoparticle etching; composited nanostructures; shape control; plasmonic sensors

\section{Introduction}

Recently, control over silver nanoparticle morphologies has received considerable attention due to their potential applications in catalysis [1,2], biological and chemical sensors [3-8] and surface-enhanced Raman spectroscopy [9-11]. Actually, for over a thousand years ago, people have used silver as an antibacterial and disinfectant as recorded in a book on Chinese herbal medicine called Compendium of Materia Medica. In decades past, synthesis of silver nanostructures has been an active research area because of their excellent optical properties such as surface-enhanced Raman scattering (SERS) [12] and plasmonic resonance, which strongly depend on size, shape and composition [13-15]. Particularly, the shape control is vital to improve the optical properties of the resulting nanostructures. Therefore, many groups have devoted their efforts to exploring ways to prepare well-defined silver nanostructures in high yields. Among the numerous methods, the chemical method is thought to be the most popular. Xia's group [16-20] successfully synthesized various well shape-controlled silver nanostructures by the polyol process in ethylene glycol (EG) through varying the precursor concentration, molar ratio of the stabilizer and silver ions, reaction temperture and addition of helper agents. However, during these processes, reaction conditions are harsh, and are complex or difficult to control. For example, the reactant injection rate is critical for the shape of the final products, which makes the procedure difficult to operate. In addition, the reaction atmosphere is very important for the synthesis of the desired silver nanostructures [21], because in the presence of oxygen, twinned particles may be etched preferentially because of higher reactivity. Conversely, without oxygen, there was no oxidation etching to dissolve twinned particles leading to the formation of silver nanowires. Helper agents such as stabilizers and some ionic species also play a great role in the shape and size control of silver nanostructures. Polyvinyl pyrrolidone (PVP) is one of common stabilizers used in the synthesis of silver nanostructures. Sun's group [22-24] produced uniform silver nanowires by taking advantage of the selectively adsorption on the (100) facets of PVP. If PVP is absent or added in low amounts, the main products are mainly nanospheres. Meanwhile, they found that silver nanoparticles with irregular morphology were formed in the presence of lower molecular weight PVP. In our previous work [25], we also demonstrated the shape of silver nanostructures can be controlled by varying the molecular weight. Wiley et al. [26] explored the role of different ions in the shape-controlled synthesis process. Results indicated that the addition of $\mathrm{Cl}^{-}$, $\mathrm{Br}^{-}$and $\mathrm{Fe}^{3+}$ promote the formation of silver nanocubes, right bipyramids and nanowires, respectively. Without fine control of reactant conditions and growth process, the obtained silver nanostructures are always obtained in low yield accompanied by large amounts of by-products. In these cases, the post processing, such as low rotation-rate centrifugation or special separation technique to purify products, is usually indispensable. Therefore, it is highly desirable to develop a reliable and facile method for the synthesis of silver nanostructures in high yield with well shape and size control.

Besides the chemical reduction method, photochemical synthesis is also applied in the preparation of silver nanostructures. Compared with chemical reduction methods, the size distribution of the nanoparticles obtained is uniform. Stabilized intermediates can be obtained, which is difficult to carry 
out by other methods. Monodisperse silver decahedrons with finely tuned sizes were produced by Pietrobon and Kitaev [15] using a novel photochemical technique. Moreover, the high symmetry and uniform size distribution causes narrow plasmon peaks with a tuned range and significant enhancement of Raman signature. Machulek Junior et al. [27] prepared silver nanoprisms in the presence of PVP via extended irradiation of nanospheres solution with visible light. Jin et al. [28] synthesized silver nanoprisms through plasmon excitation and explored the growth process in detail by analyzing TEM photographs. Although the size of nanoprisms was controlled by adjusting light wavelength, no size enlargement occurred with addition of precursors which is definitely different from thermal methods.

Although great achievements have been made in the preparation of silver nanostructures during the past decades, some issues still cannot be solved using conventional methods by simply changing the precursor concentrations or reaction temperature and time, such as tuning the size of nanoparticles over a wide range. Yang et al. [29] reviewed two kind of unconventional methods including lithography and template-based methods to fabricate metallic nanostructures with large area. Different nanostructures with uniform shapes and sizes and different composition can be produced flexibly by using templates such as ion-track etched polymer membranes or nanoporous anodized alumina membranes. Although post-processing is relative complex, which may affect the purity of products, these unconventional methods are surely efficient and powerful. Therefore, in the review we will introduce some other unconventional multistep methods which can synthesize shape-controlled and novel silver nanostructures including the double reductants method, etching technique and construction of core-shell nanostructures. Jones et al. [30] covered a number of templates for the preparation of plasmonic nanostructures including solution-phase templates, porous templates and surface mask templates. They have mentioned part of the etching technique and core-shell nanostructures in their review. However, we reviewed these unconventional methods from three perspectives following different rules. The double reductant method is based on different favorable facets of silver nanocrystals produced in different reductants. The etching technique involves the use of an etchant to selectively remove nanoparticles so that nanostructures can be obtained with shape control. The mechanism of construction of core-shell nanostructures is epitaxial growth from core seeds. The optical properties of these nanostructures can be finely tuned corresponding to the shape and size control leading to wide range of potential applications.

\section{Double Reductant Method}

It is known that different reductants can offer different reducibility, which plays an important role in shape control of nanostructures. Moreover, favorable facets of nanocrystals are determined by the reductants used. Some reductants prefer to promote growth of (100) facets, while others prefer to (111) or (110) facets. Therefore, complex nanostructures or nanostructures which are not easy to be prepared using one-step methods can be obtained by choosing different reductants in each step leading to desired nanostructures.

\subsection{N,N-dimethylformamide (DMF) and EG}

DMF is a well-known organic solvent as well as an active reductant under suitable condition which has been demonstrated [31]. Liz-Marzán's group first employed DMF to reduce $\mathrm{AgNO}_{3}$ for the preparation of silver nanostructures which paved a new way for shape control [32]. In their later works, 
they successfully synthesized nanospheres [33], nanoprisms [34,35] and nanowires [36] via reduction of $\mathrm{AgNO}_{3}$ by DMF in the presence of PVP. In addition, Gao et al. [37] prepared silver decahedrons in high yield with PVP as stabilizer in DMF. Tsuji et al. [38] provided new information on the growth of decahedrons and icosahedrons in DMF through a stepwise route. Lu et al. [39] realized the finely tuned size of nanoplates from 20 to $50 \mathrm{~nm}$ by varying the molar ratio of PVP/DMF. In DMF the main products are triangular and hexagonal plates, decahedra and icosahedra having (111) facets, as shown in Figure 1, while in EG the typical products are cubes, right-triangular, bipyramids and pentagonal rods and wires [9-11,14-16,20,40,41] having (100) facets, as shown in Figure 2.

Figure 1. SEM and TEM images of silver nanoparticles with different morphologies, prepared by reduction of $\mathrm{Ag}^{+}$ions by DMF, in the presence of PVP: (A) decahedrons (reprinted with permission from [37]. Copyright (2006), Elsevier); (B) prisms (reprinted with permission from [35]. Copyright (2009) WILEY-VCH Verlag GmbH \& Co. KGaA, Weinheim, Germany).
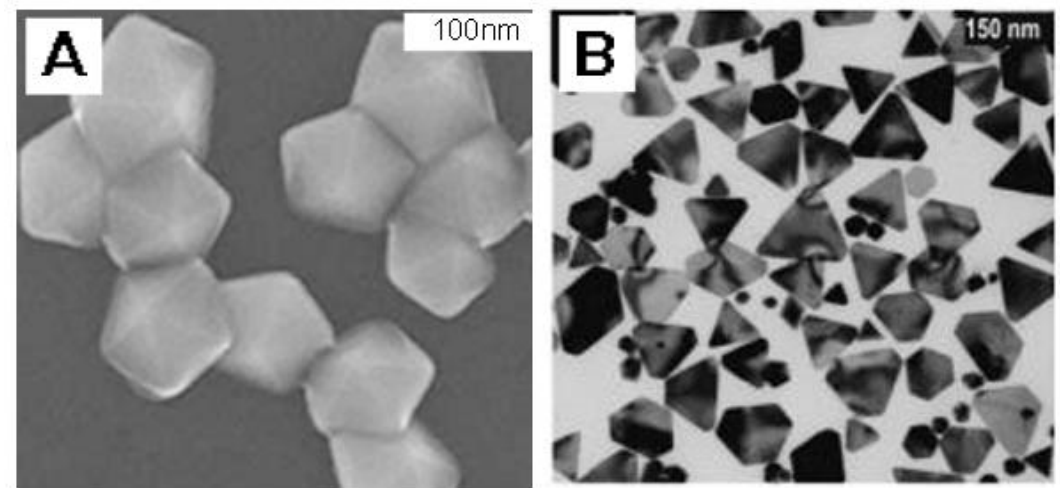

Figure 2. Electron microscopy images of single-crystal Ag nanocrystals: (A) nanocubes prepared in ethylene glycol with PVP as a capping agent; (B) nanobars prepared in ethylene glycol in the presence of PVP and $\mathrm{Br}^{-}$; (C) nanowires prepared in ethylene glycol in the presence of PVP; (D) bipyramids prepared in ethylene glycol in the presence of PVP. (reprinted with permission from [41]. Copyright (2007) American Chemical Society).

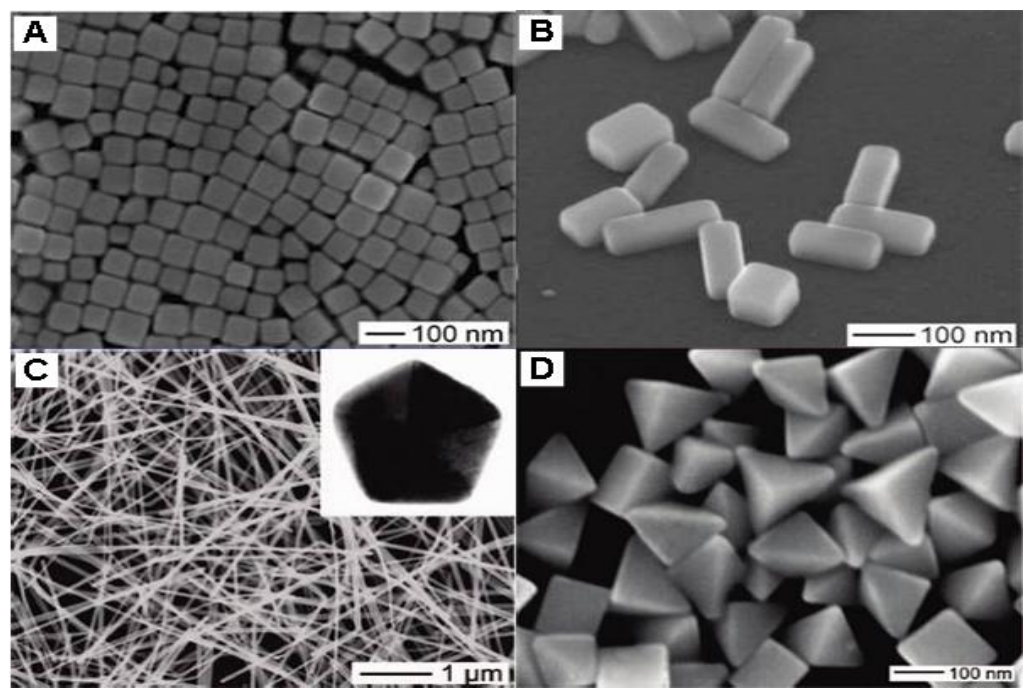


Based on this, Tsuji et al. [42] opened a new way to synthesize octahedral and triangular having (111) facets which were hard to obtain via previous methods. The production process was to prepare cubic and right bipyramids having (100) facets by reducing $\mathrm{AgNO}_{3}$ in EG first, then the shape of these nanoparticles were transformed into octahedral and triangular shapes in DMF. The shape evolution from cubic and right bipyramidal to octahedral and triangular is assigned to the different facets of $\mathrm{Ag}$ nanocrystals in EG and DMF. Sequently, they fabricated Ag nanoflags using a similar two-step method by preparing Ag nanorods as seeds in EG and growing nanoflags in DMF [43]. The following $\left[\mathrm{AgNO}_{3}\right]_{1}$ and $\left[\mathrm{AgNO}_{3}\right]_{2}$ stand for the concentration of $\mathrm{AgNO}_{3}$ in the first and second step respectively. In the first step silver nanorod as shown Figure 3a was prepared by reduction of $\mathrm{AgNO}_{3}$ in $\mathrm{EG}$ in the presence of PVP, and then was dispersed in DMF as a seed solution. In the second step, seed solution was added into a DMF solution containing $\mathrm{AgNO}_{3}$ and PVP. With the increase of the ratio of $\left[\mathrm{AgNO}_{3}\right]_{2} /\left[\mathrm{AgNO}_{3}\right]_{1}$, different structures were observed (Figure 3b-f). They explained the growth mechanism of silver nanoflags from nanorods in detail as shown in Figure 4. In the second step, a trapezoid plate formed from the side surface of silver nanorods, and then grew into a triangular twin plate. Next the triangular flags transformed into tetrahedral flags via two routes. As route 1a in Figure 4 shows, another triangular flag formed in another side of the silver nanorod, and then grew to the other one until the two triangular flags connected together leading to tetrahedral flags. The other route (route $1 \mathrm{~b}$ in Figure 4 ) is that two triangular pyramidal structures grew from the former triangular flags and finally evolved into tetrahedral flags. If $\left[\mathrm{AgNO}_{3}\right]_{2}$ is too high, the tetrahedral flags can continue to grow into twin tetrahedral flags which can be seen from route 1c in Figure 4. Therefore, the double reductant method gives a new way to manufacture octahedral, triangular and novel silver nanostructures in high yield and well-controlled in size and shape which are difficult to obtain via one-step methods.

Figure 3. TEM images of $\mathrm{Ag}$ rod seeds and flag types of $\mathrm{Ag}$ nanostructures prepared in $\mathrm{DMF}$ at various $\left[\mathrm{AgNO}_{3}\right]_{2} /\left[\mathrm{AgNO}_{3}\right]_{1}$ ratios (reprinted with permission from [43]. Copyright (2010) American Chemical Society).

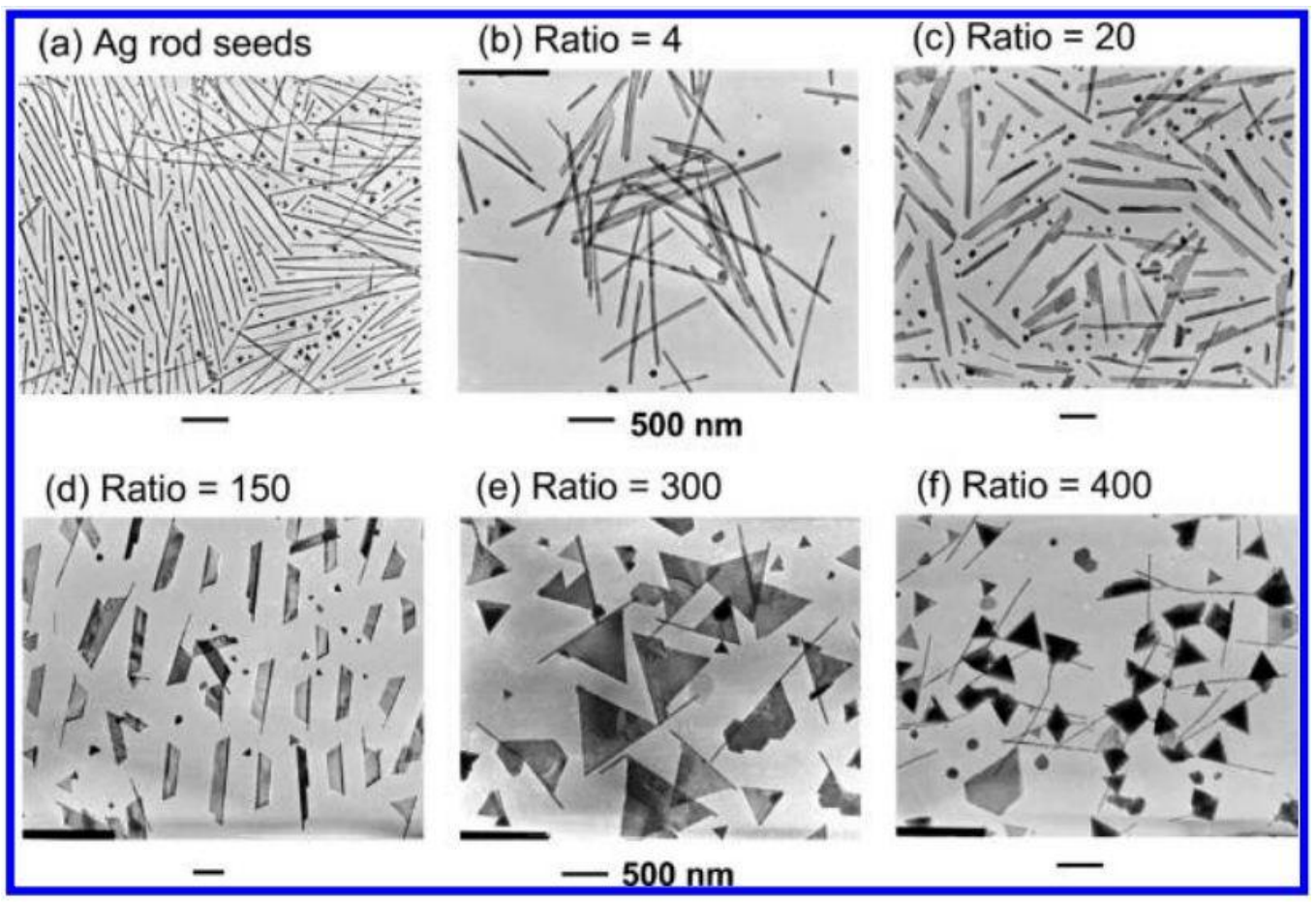


Figure 4. Growth mechanisms of silver nanoflags from silver nanorods in DMF (reprinted with permission from [43]. Copyright (2010) American Chemical Society).

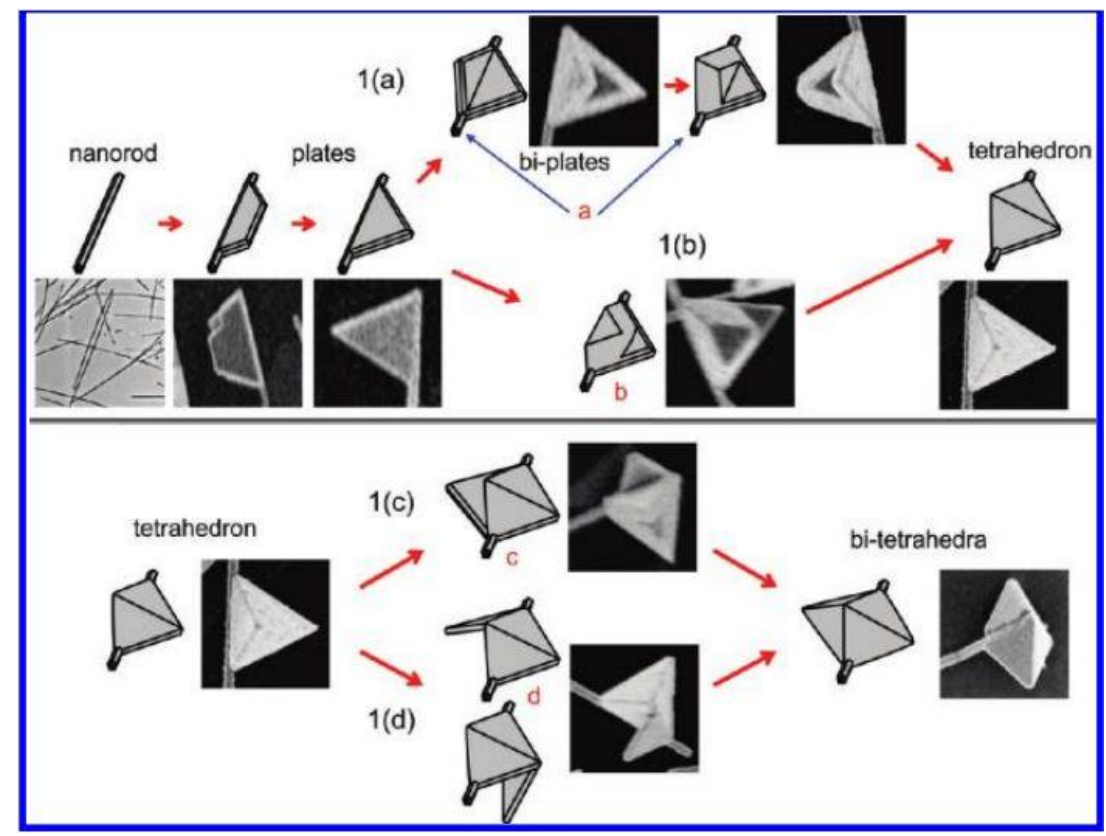

\subsection{Sodium Borohydride $\left(\mathrm{NaBH}_{4}\right)$ and Ascorbic Acid (AsA)}

Aside from EG and DMF, $\mathrm{NaBH}_{4}$ is also frequently used as a reductant to synthesize nanosized $\mathrm{Ag}$ colloids. Many groups have studied the reduction of $\mathrm{Ag}^{+}$ion in $\mathrm{NaBH}_{4}$ which is usually used with some stabilizer, such as citrate and PVP. Zhang et al. [44] explored a new way to control the size and shape of $\mathrm{Ag}$ nanospheres by changing the rate of nucleation and growth in the reduction of $\mathrm{Ag}^{+}$ion by $\mathrm{NaBH}_{4}$ together with trisodium citrate $\left(\mathrm{Na}_{3} \mathrm{CA}\right)$ and PVP. In the absence of $\mathrm{Na}_{3} \mathrm{CA}$, nanospheres cannot be prepared because Ag nucleuses are immediately protected by PVP as soon as they form leading to the anisotropic growth of Ag nanoparticles due to selective adsorption of PVP on the (100) facets. When PVP was absent, the products were also nanospheres with larger size. The results indicate that the role of $\mathrm{Na}_{3} \mathrm{CA}$ is to promote the reduction of $\mathrm{Ag}^{+}$ion into nanospheres. On the other hand, PVP can promote nucleation and prevent the aggregation of nanoparticles. In our previous work [45], we prepared branched silver nanowires and nanomeshworks by using both $\mathrm{NaBH}_{4}$ and $\mathrm{Na}_{3} \mathrm{CA}$ in the presence of PVP. Silver seeds were prepared firstly, and then exposed under light leading to aggregation and were thus welded together, so the final morphology was decided by the concentration of PVP. Wojtysiak [46] also studied the important effect of citrate on the reduction of $\mathrm{Ag}^{+}$ions by $\mathrm{NaBH}_{4}$. Stable $\mathrm{Ag}$ nanoclusters only appeared when citrate was added, otherwise reduction of $\mathrm{Ag}^{+}$ion by $\mathrm{NaBH}_{4}$ under the conditions with citrate led to a precipitate at the bottom of solution. Citrate is a stabilizer as well as a reductant. In this regard, Yi et al. [47] used $\mathrm{NaBH}_{4}$ and $\mathrm{Na}_{3} \mathrm{CA}$ as a double reductant system to prepare $\mathrm{Ag}$ nanoplates via a multistage procedure. In the first stage, Ag nanoplates were prepared as seeds with $\mathrm{NaBH}_{4}$ and $\mathrm{Na}_{3} \mathrm{CA}$. Then these as-prepared seeds evolved into larger nanoplates with tunable sizes of $40 \mathrm{~nm}$ to $260 \mathrm{~nm}$ by adding different volumes of $\mathrm{Na}_{3} \mathrm{CA}$ solution. Each addition of $\mathrm{Na}_{3} \mathrm{CA}$ solution and seed solution was named one stage, the size of the nanoplate increased without change of shape, and the SPR peak shifted red. To get triangular nanoplates with satisfactory size distribution and yield, Yang et al. [48] applied a novel double reductant method which consists of three steps. In the first step, silver nanospheres 
were prepared through reduction of $\mathrm{AgNO}_{3}$ by $\mathrm{NaBH}_{4}$ in the presence of $\mathrm{Na}_{3} \mathrm{CA}$. In the second step, sodium dodecyl sulfate (SDS) was added as stabilizer into the as-prepared silver nanoparticle colloid and then citrate-stabilized silver nanospheres were converted into SDS-stabilized silver nanospheres. In the last step, silver nanoplates were formed under the reduction of SDS-stabilized silver nanospheres by citrate and aged in $\mathrm{NaCl}$ solution. When SDS-stabilized silver nanospheres aged in $\mathrm{NaCl}$ solution for one week, they began to transformed into nanoplates. Three weeks later, high-yield silver nanoplates with larger size were formed. In their further experiments, if only $\mathrm{NaBH}_{4}$ was used as reductant in the presence of SDS, no silver nanoplates appeared, which indicated citrate is essential to reduce SDS-stabilized silver nanospheres in the third step.

More recently, a method of using AsA to prepare unique silver nanostructures such as flower-like and string forms has been developed [49]. Zheng et al. [50] got silver dendrites when they reduced $\mathrm{AgNO}_{3}$ by AsA in the presence of cetyltrimethylammonium bromide (CTAB) and SDS. Lou et al. [51] also found that hyperbranched silver nanostructures can be obtained by reduction of $\mathrm{AgNO}_{3}$ by AsA with $\mathrm{Na}_{3} \mathrm{CA}$. Based on these researches of hyperbranched silver nanostructures mentioned above, Wang et al. [52] explored the growth mechanism of hyperbranched silver nanostructures in AsA. In their opinion, as Figure 5a shows, multifaceted particles with bulbous tips were formed from the reduction of $\mathrm{AgNO}_{3}$ by AsA in the initial stage of reaction, which are easy to aggregate in AsA [53]. After 20-30 s, silver atoms were deposited on the bulbous ends of the seeds resulting in the growth of the branched particles (Figure 5b. Figure 5c,d illustrate that with longer reaction time, the size continues to increase and secondary branches began to grow from the first branches that originate from the seeds. Moreover, tips can be observed at the ends of branches. In addition to AsA which acts as a key factor in the formation of branched structures, stabilizers such as starch [54] and PEO-PPO-PEO tri-block copolymer [55] also play an important role in controlling the morphology of silver nanostructures. Besides, a method of using AsA to prepare a series of silver nanostructures by reducing $\mathrm{AgCl}$ in aqueous solution has been developed by Chen et al. [56]. Their key idea for growing different morphologies silver nanoparticles is to adjust amount of sodium hydroxide $(\mathrm{NaOH})$. Because the reduction power of AsA is related to $\mathrm{pH}$ which can be varied by adding $\mathrm{NaOH}$, silver nanoparticles seeds of different sizes were prepared firstly in the presence of AsA and $\mathrm{NaOH}$, and then $\mathrm{AsA} / \mathrm{AgCl} / \mathrm{PVP} / \mathrm{NaOH}$ solution system was added to control the shape. Taking $50 \mathrm{~nm}$ silver seeds as an example, Figure 6 shows FE-SEM images of silver nanostructures obtained from as-prepared seeds in AsA with different dosages of $\mathrm{NaOH}$. Furthermore, they follow the formula (1) to predict the size of the product:

$$
\mathrm{D}=\mathrm{d} \times \sqrt[3]{\frac{\mathrm{N}+\mathrm{n}}{\mathrm{n}}}
$$

In the formula, $\mathrm{D}$ is the average size of product, $\mathrm{d}$ is the average size of seeds, and $\mathrm{N}$ and $\mathrm{n}$ are the molar amount of $\mathrm{AgCl}$ and seeds respectively. They fixed the amount of $\mathrm{AgCl}$, and used $50 \mathrm{~nm}$ silver nanoparticles as seeds, so in theory if they want obtain the products with 100, 150, 200, $250 \mathrm{~nm}$, the $(\mathrm{N}+\mathrm{n}) / \mathrm{n}$ should be 8, 27, 64, and $125 \mathrm{~nm}$ respectively. As shown in Figure 7, the experiment results are consistent with the prediction. 
Figure 5. SEM images of the silver particles sampled at different reaction times (A) 3-8 s; (B) 20-30 s; (C) $1 \mathrm{~min}$; and (D) $5 \mathrm{~min}$. Arrows indicate examples of tip splits (reprinted with permission from [52]. Copyright (2008) American Chemical Society).
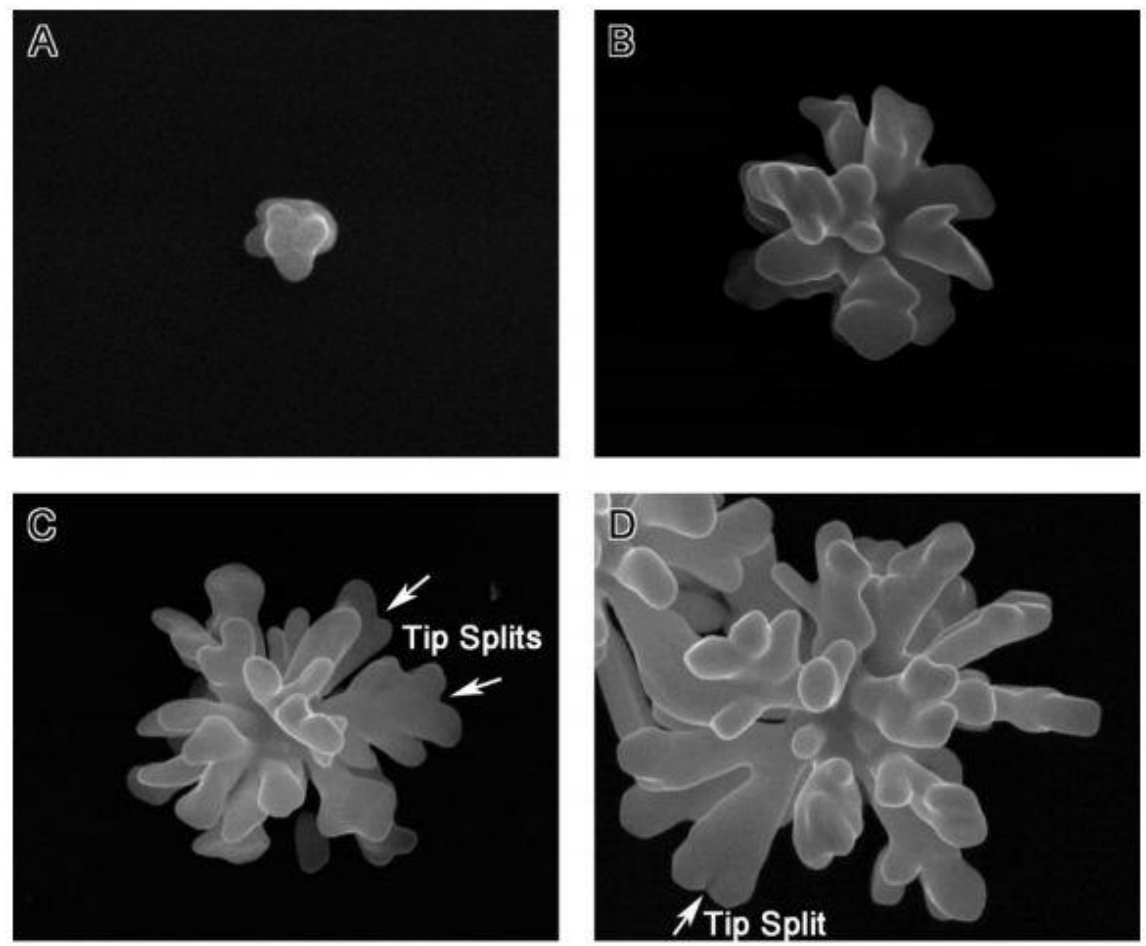

$200 \mathrm{~nm}$

Figure 6. Inhibition of the anisotropic growth of Ag crystals: (a) sketch of the twinned decahedron, rod- and wire-shaped crystals; (b) FE-SEM image, indicating the adsorption of PVP on the surface of a Ag particle; (c) TEM image of as-prepared $50 \mathrm{~nm} \mathrm{Ag}$ particles; (d-h) HR-TEM images of as-prepared $50 \mathrm{~nm} \mathrm{Ag} \mathrm{particles} \mathrm{for} \mathrm{the} \mathrm{particles} \mathrm{with} \mathrm{the} \mathrm{shape} \mathrm{of}$ decahedron, icosahedron, quasi-sphere, cube, and hexagon, respectively; insets are sketches of the corresponding structures (reprinted with permission from [56]. Copyright (2010) American Chemical Society).
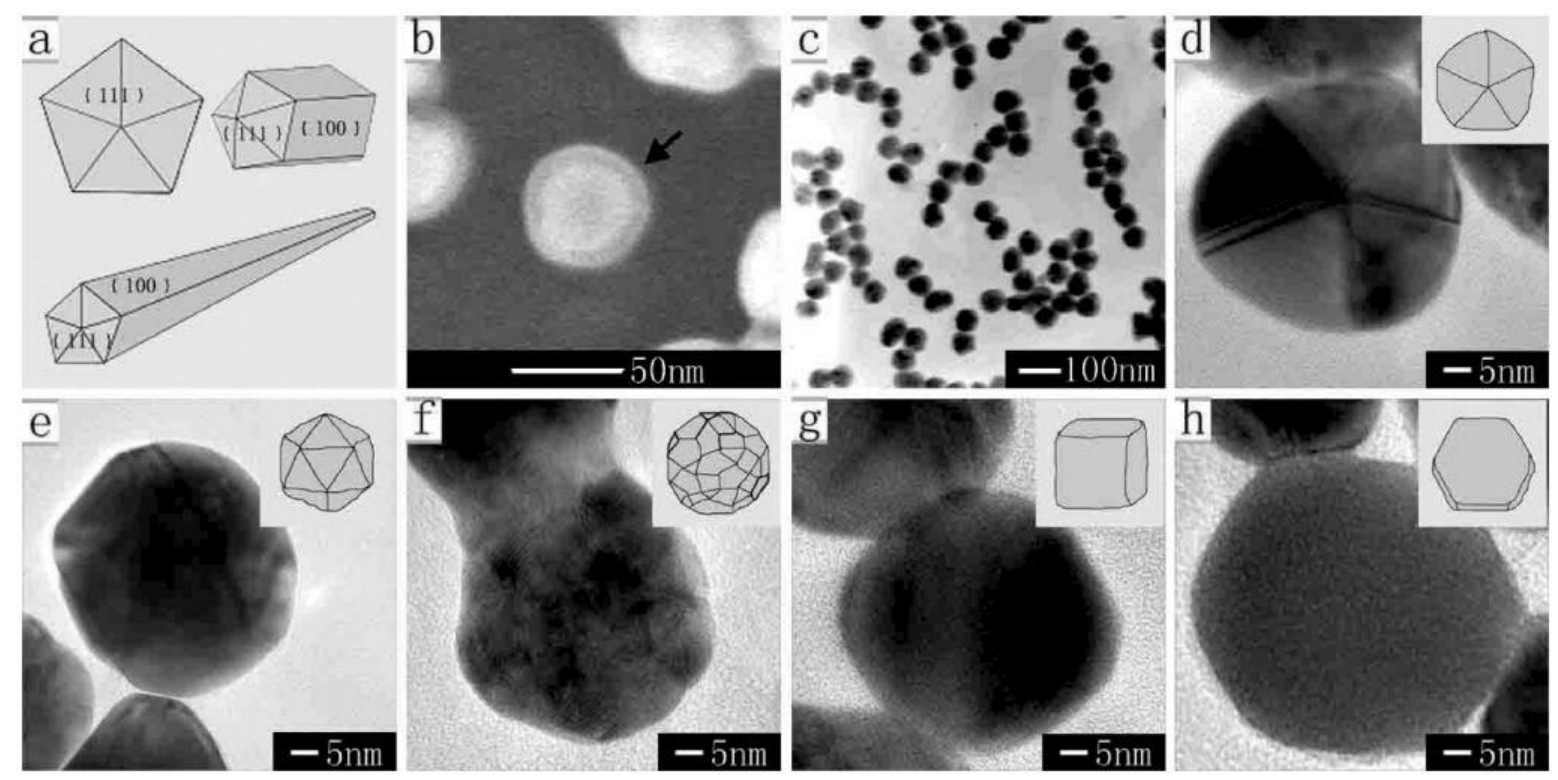
Figure 7. FE-SEM images of $50 \mathrm{~nm} \mathrm{Ag} \mathrm{seeds} \mathrm{(a)} \mathrm{and} \mathrm{as-prepared} \mathrm{products} \mathrm{of} \mathrm{quantitative}$ size-controlled and size-designed synthesis with sizes of (b) $100 \mathrm{~nm}$; (c) $150 \mathrm{~nm}$; (d) $200 \mathrm{~nm}$; and (e) $250 \mathrm{~nm}$. Reaction times are $16 \mathrm{~h}$, insets are the corresponding size-distribution histograms; (f) shows the XRD patterns corresponding to (a-e) (reprinted with permission from [56]. Copyright (2010) American Chemical Society).

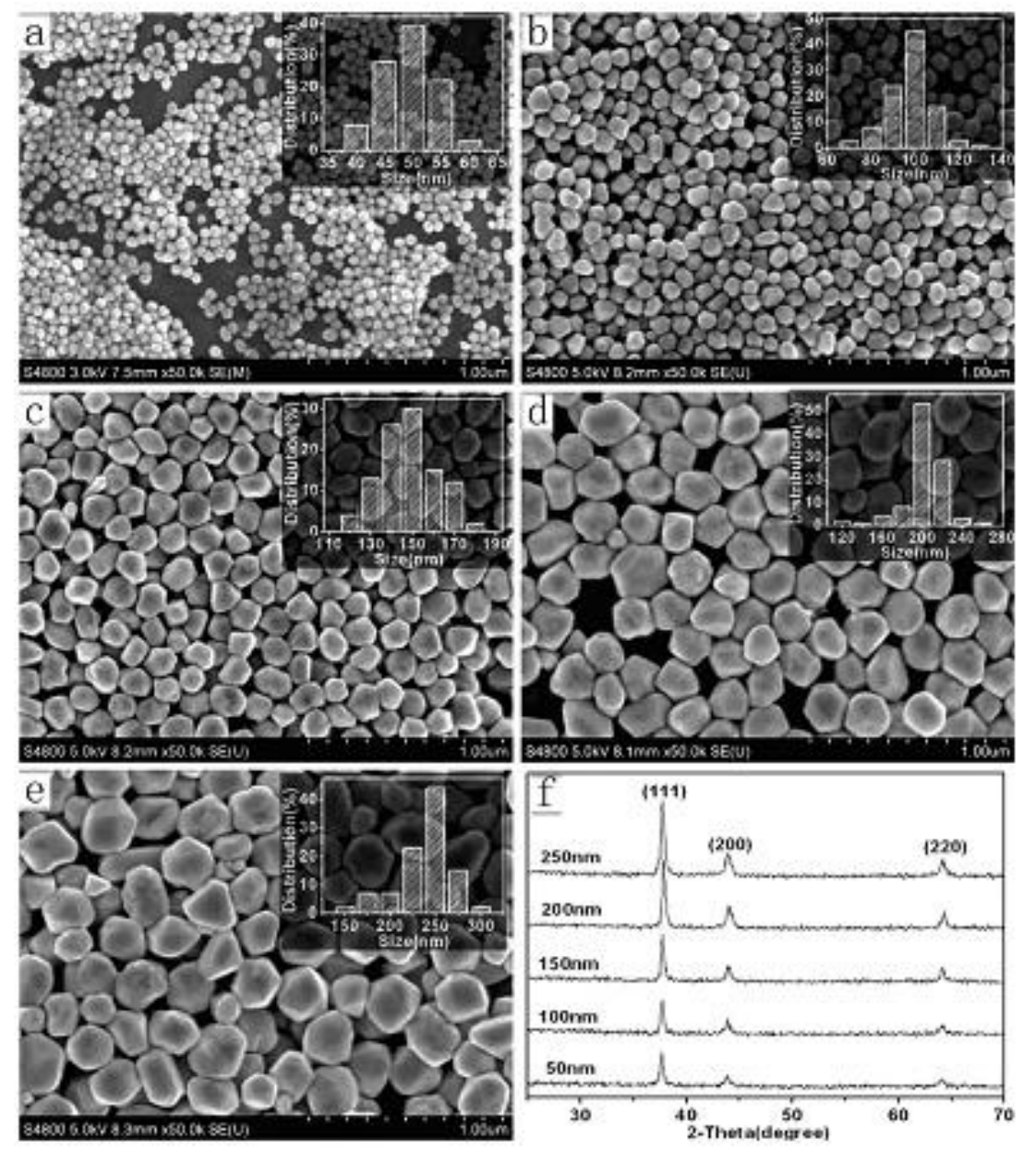

Above all, we can get a conclusion which is that the products tend to be nanospheres of small sizes in $\mathrm{NaBH}_{4}$ which are usually used as seeds for further growth of silver nanocrystals, while silver nanoparticles are easy to aggregate together in AsA. Samanta [57] presented a two-step method to produce silver nanodiscs and triangular nanoplates with both $\mathrm{NaBH}_{4}$ and AsA as double reductants. They prepared $\mathrm{Ag}$ nanoparticles in $\mathrm{NaBH}_{4}$ in the first step. When these nanoparticles used as seeds with different amounts were added into $\mathrm{AgNO}_{3}$ solution in AsA, silver nanodiscs and triangular nanoplates formed, respectively. A high yield of triangular nanoplates can be obtained in lower amount of seed solution which provides a new path to synthesize triangular nanoplates.

\section{Etching Technique}

Recently, shape and size control as well as novel nanostructures which can increase SERS enhancement have attracted more attention. The optical properties of nanostructures can be tuned by varying their sizes, therefore it is vital to provide a way to control the size. In addition, these nanostructures with sharp horns such as nanoflowers or nanostars can focus the electromagnetic field on their tips leading to significant 
SERS effect. The etchant technique can not only control shapes and sizes of nanostructures, but also creates novel nanostructures with hot spots or hollow nanostructures.

\subsection{Hydrogen Peroxide $\left(\mathrm{H}_{2} \mathrm{O}_{2}\right)$}

Early in the 1950 s, $\mathrm{H}_{2} \mathrm{O}_{2}$ is used to etch pits in metals, which plays an important role of dislocations in determining or affecting the mechanical properties of crystalline materials [58]. The standard potential in the $\mathrm{H}_{2} \mathrm{O}_{2}$ - water couple is dependent on the $\mathrm{pH}$ value of the solution. In acidic solutions:

$$
\mathrm{H}_{2} \mathrm{O}_{2}+2 \mathrm{H}^{+}+2 \mathrm{e}^{-} \rightarrow 2 \mathrm{H}_{2} \mathrm{O} \quad E^{0}=1.763 \mathrm{~V}
$$

In alkaline solutions:

$$
\mathrm{H}_{2} \mathrm{O}_{2}+2 \mathrm{e}^{-} \rightarrow 2 \mathrm{OH}^{-} \quad E^{0}=0.867 \mathrm{~V}
$$

Because the potentials are higher than that of $\mathrm{Ag}^{+} / \mathrm{Ag}\left(E^{0}=0.7996 \mathrm{~V}\right)$ [59], $\mathrm{H}_{2} \mathrm{O}_{2}$ can be used as an effective etchant to dissolve metallic silver. Very recently, etching techniques are used for controlling the shapes of Ag nanoparticles because some nanostructures are not easily prepared in high yield or mono-dispersed sizes.

Among these various shapes, Ag nanoprisms and triangulars have attracted intense interest due to their unique optical properties and related applications. Generally, two main methods have been developed to prepare Ag nanoprisms, including the photochemical method and chemical reduction method. Compared with the photochemical method [60-63], the chemical reduction method is considered a popular and a simple route, however, this method cannot provide relative uniform size distributions. M'etraux and Mirkin [64] reported a new chemical reduction route to prepare Ag nanoprisms which is a great breakthrough in the size control of silver nanostructures. In the process, in the absence of $\mathrm{H}_{2} \mathrm{O}_{2}$, the products were nanospheres, which indicated that $\mathrm{H}_{2} \mathrm{O}_{2}$ plays a critical role of $\mathrm{Ag}$ nanoprism formation. Sequentially, Zhang et al. [65] studied in detail the role of $\mathrm{H}_{2} \mathrm{O}_{2}$ in the same reaction system. They proposed that $\mathrm{H}_{2} \mathrm{O}_{2}$ can remove the relatively unstable nanoparticles in the nucleation stage and promote the formation of anisotropic structures, finally all metallic silver particles can be directly transformed into silver nanoplates regardless of size and shape, but if the concentration of $\mathrm{H}_{2} \mathrm{O}_{2}$ was too high, the obtained nanoprisms also would be etched and disappear. To further study the mechanism, Tsuji et al. [66] examined the relative etch rate of prism to sphere by monitoring the time-dependent SPR band of the mixture of spheres and prisms. Similarly, they used a flag type of Ag nanostructure which contained triangular plates and a pentagonal rod to examine the relative etch rate of prism to rod. The results were: $v_{\text {prism }}<v_{\text {sphere }}$ and $v_{\text {prism }}<v_{\text {rod }}$. If either $\mathrm{H}_{2} \mathrm{O}_{2}$ or $\mathrm{Na}_{3} \mathrm{CA}$ is absent, the transformation from spheres to prisms will not happen and $\mathrm{Na}_{3} \mathrm{CA}$ must be added before $\mathrm{H}_{2} \mathrm{O}_{2}$. The major difference between the method and Zhang's is that the etching of metallic $\mathrm{Ag}$ nanostructures and reduction of $\mathrm{Ag}^{+}$ion occur at the same time in the latter reaction process, but the former argued that the first step is complete dissolution of $\mathrm{Ag}$ nanowire to $\mathrm{Ag}+$ ion and then reduction of $\mathrm{Ag}^{+}$ion to $\mathrm{Ag}^{0}$. They also successfully prepared $\mathrm{Ag}$ nanoprisms from nanocubes and nanobipyramids. This essay made a great contribution to preparing high-yield Ag nanoprisms from different metallic Ag nanostructures. Figure 8 presents the growth mechanisms of silver nanoprisms from the mixture of spherical nanoparticles and prisms and nanorods, cubes, and bipyramids. 
Figure 8. Growth mechanisms of ag nanostructures prepared from mixtures of spherical nanoparticles and prisms and nanorods, cubes, and bipyramids (reprinted with permission from [66]. Copyright (2012) American Chemical Society).

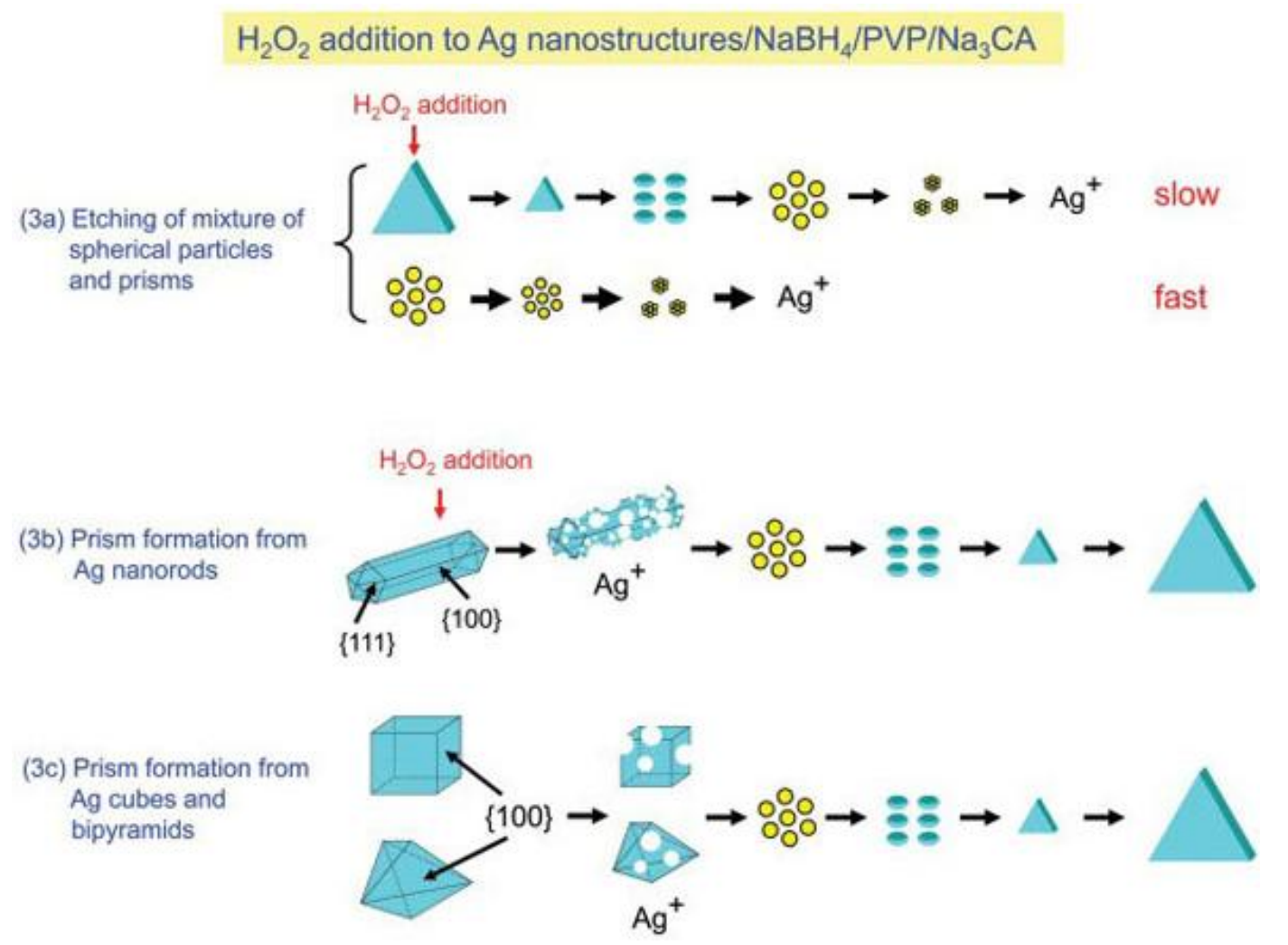

Recently, metallic hollow nanostructures such as cages [67-70] and frames [71,72] which have bigger surface area have aroused intense interest because they can broadly tune localized surface plasmon resonance (LSPR) and exhibit excellent optical, electronic and catalytic properties. Zhang et al. [73] explored a new method based on $\mathrm{H}_{2} \mathrm{O}_{2}$ etching to prepare Au nanoboxes. Because the standard reduction potential of $\mathrm{AuCl}_{4}{ }^{-} / \mathrm{Au}$ is higher than that of $\mathrm{Ag}^{+} / \mathrm{Ag}, \mathrm{Au}$ can be replaced by $\mathrm{Ag}$ following Equation (4):

$$
3 \mathrm{Ag}(s)+\mathrm{AuCl}_{4}^{-}(l)=\mathrm{Au}(s)+3 \mathrm{AgCl}(s)+\mathrm{Cl}^{-}(l)
$$

Based on the chemical equation, silver nanoboxes can be transformed into gold nanoboxes. The synthesis procedure is to form $\mathrm{Au}-\mathrm{Ag}$ alloy nanoboxes by titrating $\mathrm{Ag}$ nanocubes with aqueous $\mathrm{HAuCl}_{4}$. By controlling the amount of $\mathrm{HAuCl}_{4}$ aqueous, they can precisely control the thickness of nanoboxes via titrating $\mathrm{HAuCl}_{4}$ aqueous solution as presented in Figure 9a-d, causing the redshift of LSPR peaks. Then $\mathrm{Ag}$ atoms are removed from the nanoboxes and alloy walls via $\mathrm{H}_{2} \mathrm{O}_{2}$ etching. Figure $9 \mathrm{e}-\mathrm{h}$ show the corresponding Au-based nanocages after the addition of excess $\mathrm{H}_{2} \mathrm{O}_{2}$. McEachran et al. [74] proposed a similar pathway to synthesize well-defined gold nanoframes from decahedral silver nanoparticals, but unlike Xia et al. they controlled the thickness of frames by adjusting the amount of deposited gold. Furthermore, they attempted to make similar nanoframes using other silver nanostructures. Results indicated that only nanostructures with (111) facets such as nanorods and icosahedra can be used for the formation of nanoframes. They argued that gold prefers to deposit on the (111) facets, whereas (100) facets are more reactive to cause nanocages or nanoshells. We believe that the etching technique is a facile method to prepare hollow nanostructures with well-controlled shapes and sizes. 
Figure 9. TEM images of $\mathrm{Au}$-Ag nanoboxes before and after etching with an excess amount of $\mathrm{H}_{2} \mathrm{O}_{2}$ : (A-D) the Au-Ag nanoboxes with their LSPR peaks being tuned to 460, 520, 675, and $745 \mathrm{~nm}$, respectively, prior to the addition of $\mathrm{H}_{2} \mathrm{O}_{2}$; and $(\mathbf{E}-\mathbf{H})$ the corresponding Au-based nanocages after the addition of excess $\mathrm{H}_{2} \mathrm{O}_{2}$ (reprinted with permission from [73]. Copyright (2010) American Chemical Society).
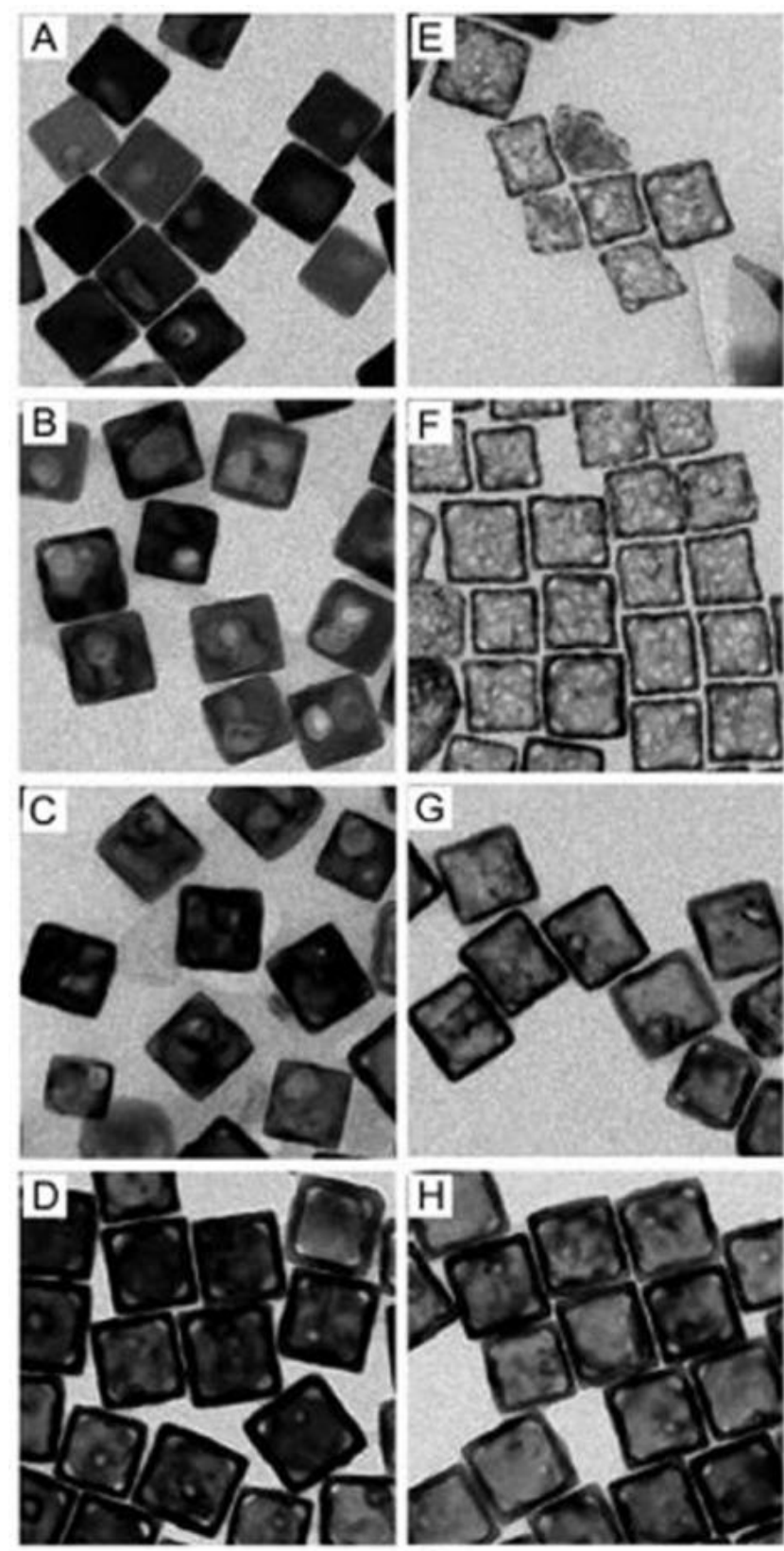

$50 \mathrm{~nm}$

It is well known that nanostructures with sharp edges or gaps can enhance SERS intensity [75-78], therefore the etching technique can also be applied to prepare flower-like silver nanostructures or make the surface of nanocrystals rough. For example, Yang et al. [79] etched silver nanooctahedra by $\mathrm{H}_{2} \mathrm{O}_{2}$ and $\mathrm{NH}_{4} \mathrm{OH}$ mixtures. From Figure 10 we can see that the intensity of extinction significantly increases along with the etching progress and the octopod structures have LSPR with greater intensity in the near-infrared regions (red line in Figure 10). They presented a novel etching technique for synthesis of complex nanostructures which have broad range of resonance band and strong enhancement of SERS 
signals. Another method increasing the intensity of SERS is to fabricate nanostructures with hot spots. The definition of hot spots is the junctions or gaps between two or more closely spaced nanoparticles in which enormous electromagnetic enhancements are generated in contrast to individual particles [80]. The formation of hot spots has attracted much attention, including the theoretical aspects of electromagnetic enhancement factors in SERS [81] and experimental fabrication of nanostructures with hot spots [82-84]. In theory, Ag nanowire is an ideal nanostructure with large surface to be a SERS substrate, however, the smooth surface limits the ability to form localized surface plasmons. To solve the problem, Goh et al. [85] increased the number of SERS hot spots on the surface of silver nanowires by etching in $\mathrm{H}_{2} \mathrm{O}_{2}$ and $\mathrm{NH}_{4} \mathrm{OH}$ mixture resulting in a $10^{4}$-fold enhancement of SERS compared with that obtained by pre-etching. Some ways have been reported to attach nanoparticles onto nanowires [86-89], however, the enhancement of SERS is strongly related to the interaction between nanowires and nanoparticles rather than localized surface plasmons. It is asserted that the etching technique can be widely used for the fabrication of SERS substrates with potential applications in many areas.

Figure 10. UV-vis-NIR spectra of different stages of the etching progress when starting from octahedral nanoparticles. Interestingly, as the etching progresses the octopod structures have LSPs with greater intensity in the red and near-infrared regions (reprinted with permission from [79]. Copyright (2010) American Chemical Society).

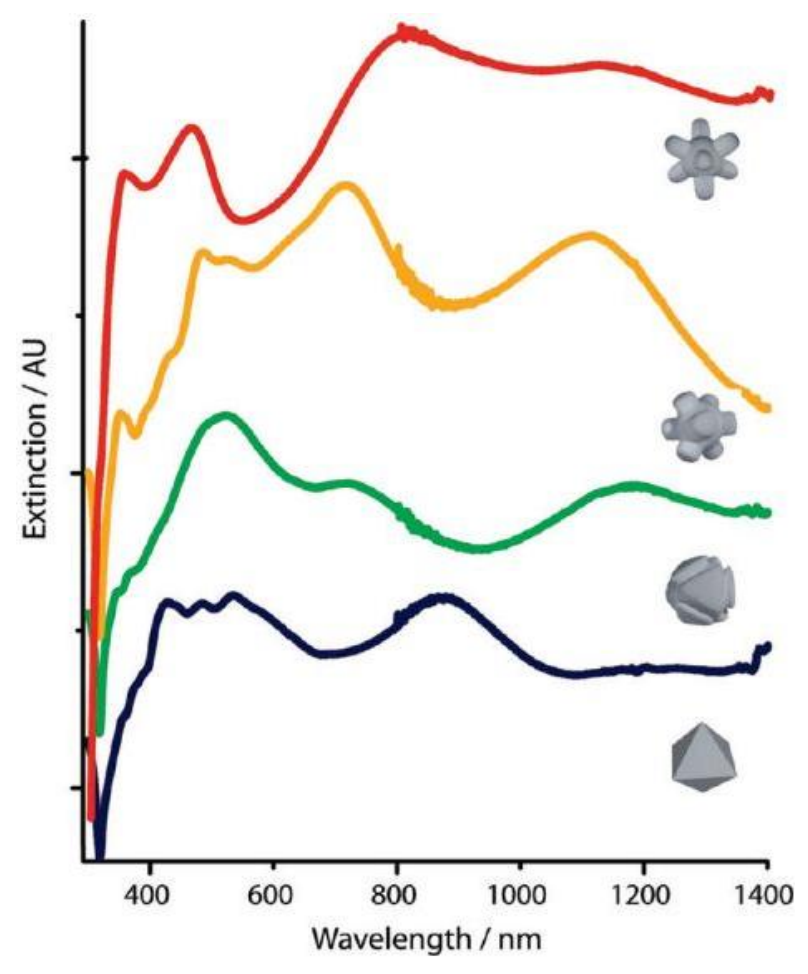

\subsection{Other Etchants}

There are many other etchants applied to modify the morphology of silver nanoparticles, such as $\mathrm{NH}_{4} \mathrm{OH}$ or $\mathrm{Fe}\left(\mathrm{NO}_{3}\right)_{3}$. Sometimes $\mathrm{NH}_{4} \mathrm{OH}$ is used with $\mathrm{H}_{2} \mathrm{O}_{2}$, which has been discussed in Section 3.1., therefore we will not reintroduce it here. Lu et al. [90] found that $\mathrm{NH}_{4} \mathrm{OH}$ or $\mathrm{Fe}\left(\mathrm{NO}_{3}\right)_{3}$ play an important role in the formation of Au nanoboxes. The process consists two steps as follows: (1) preparation of $\mathrm{Au} / \mathrm{Ag}$ alloy nanoboxes through depositing Au on the surface of Ag nanocubes; (2) removal of Ag from 
$\mathrm{Au} / \mathrm{Ag}$ alloy nanoboxes via etching by $\mathrm{NH}_{4} \mathrm{OH}$ or $\mathrm{Fe}\left(\mathrm{NO}_{3}\right)_{3}$. After the formation of the $\mathrm{Au}$ nanobox, sequent addition of $\mathrm{NH}_{4} \mathrm{OH}$ or $\mathrm{Fe}\left(\mathrm{NO}_{3}\right)_{3}$ causes the transformation into nanocages and nanoframes. Another advantage of this method is that $\mathrm{NH}_{4} \mathrm{OH}$ or $\mathrm{Fe}\left(\mathrm{NO}_{3}\right)_{3}$ can selectively remove $\mathrm{Ag}$ from the walls of $\mathrm{Au} / \mathrm{Ag}$ alloy nanoboxes leading to good control in the thickness of nanocages which is difficult to achieve by other methods.

\section{Construction of Core-Shell Nanostructures}

Although Ag nanostructures have received considerable attention because of their excellent optical properties and wide applications in many areas, people still attempt to develop novel nanostructures for higher requirements. The optical properties of nanostructures can also be tailored by controlling their elemental composition, as well as the internal and surface structures. Most recently, special attention has been paid to core-shell nanostructures because they provide a new system with tunable optical properties. In this case, core-shell nanostructures can be achieved through various methods which have been developed, such as chemical reduction method, nanosphere lithography (NSL) [91,92], photochemical method [93-96].

\subsection{Au@Ag Core-Shell Nanostructures}

$\mathrm{Au} @ \mathrm{Ag}$ core-shell nanostructures exhibit finely tuned LSPR and SERS properties based on the shape and size, and have potential applications in sensors [91,97-99] and catalysis [100], thus many attempts have been made to prepare these nanostructures.

The shape and size of the Au core is important for the evolution of Ag on Au nanoparticles. Many groups select Au nanorods as cores to construct the Au@ Ag core-shell nanostructures to which excellent optical properties are ascribed. Liu et al. [101] described two different routes to coat the Au nanorods with silver for the first time. One way is to reduce $\mathrm{AgNO}_{3}$ by AsA on the surface of Au nanorods with sodium citrate used as stabilizer, but the repeatability of results is not good and it is difficult to take TEM pictures due to the high concentration of sodium citrate. In this regard, they chose PVP as stabilizer instead of sodium citrate. However, they found that $\mathrm{Ag}^{+}$ions cannot be reduced in low $\mathrm{pH}$ solution, because the redox potential of AsA varied with $\mathrm{pH}$ until it was sufficient to overcome that of $\mathrm{Ag}$. Therefore, when $\mathrm{NaOH}$ was added or AsA was replaced by citric acid which is a weak acid, Ag shells formed. The results indicated that with the increased amount of $\mathrm{AgNO}_{3}$ added, the thickness of the $\mathrm{Ag}$ shell increased and the blue-shift of the longitudinal plasmon mode of the nanorods was enhanced. Later on, Seo et al. [102] demonstrated that Ag nanorods can be grown directly from Au decahedrons and nanorods. Benefiting from the success of Seo in forming Au@ Ag core-shell nanorods from Au decahedron seeds, we can get a deeper understanding of the growth mechanism of nanorods. In the initial stage, $\mathrm{Ag}^{+}$ ions were reduced and deposited on the decahedral seeds. Then, Ag nanocrystals grew along the longitudinal direction with slight changes along the lateral direction assigned to the selective adsorption of PVP on the (100) facets. The results correspond to the growth mechanism of Ag nanorods proposed by Xia et al. However, in the research of Xia et al. [103], the morphology of Ag nanoparticles were octahedrons grown from Au nanorods. They explained that Au@ Ag core-shell nanorods were transition modes, when more Ag was deposited, (100) and (110) facets began to disappear and the nanorods finally evolved into octahedrons. In addition, they can easily tune the size of Ag octahedrons by using $\mathrm{Au}$ nanorods with different aspect ratios or controlling the amount of $\mathrm{AgNO}_{3}$ added to the reaction system. 
In the case of other Au nanorods as seeds, Sanchez-Iglesias et al. [104] also produced Ag octahedron shelsl from Au nanorods in a different way. Compared with the work of Xia et al. [103], they controlled the thickness of Ag shells from thin to thick not only by using different aspect ratios of Au nanorods, but also using methoxypoly(ethylene glycol)-thiol (mPEG-SH) as stabilizer which can bind at the Au nanorod tips to block the growth of $\mathrm{Ag}$ along the longitudinal direction leading to the formation of $\mathrm{Ag}$ octahedrons. Moreover, they demonstrated that the optical properties of these core-shell constructs can be finely tuned with the change of thickness of Ag shell and the Au@Ag core-shell octahedrons with thin shells showing optical properties similar to those of pure Ag octahedrons.

As with the above-mentioned Ag nanoprisms and triangular synthesized by $\mathrm{H}_{2} \mathrm{O}_{2}$ etching, additional seed-mediated growth method are often used to construct Au@ Ag core-shell nanoprisms and triangulars. Xue et al. [96] reported a photochemical method to form Au@ Ag core-shell nanoprisms. In their experiments, the role of Au seed was as a photocatalyst leading to the growth of Ag triangular shells which slightly depended on the shape of the Au cores. However, the morphology of Ag triangles can be easily tuned by changing the excitation wavelength and size of the Au core. In 2009, their group produced Au@Ag core-shell triangular bifrustums via chemical reduction route by AsA [100]. Compared with the photocatalyst they used, the sizes of Ag triangles were bigger and the triangular bifrustum became thicker with the increase of the addition amount of $\mathrm{AgNO}_{3}$, significantly affecting the SPR spectrum. Recently, Tsuji's group developed a combination of microwave and polyol reduction route to prepare Au@Ag core-shell triangles [94] as Figure 11 shown. In the first step, Au nanocrystals seeds were obtained by reducing $\mathrm{HAuCl}_{4}$ in $\mathrm{EG}$ in the presence of PVP under microwave heating conditions. In the second step, as-prepared Au seeds were added into a DMF solution of $\mathrm{AgNO}_{3}$ to form Ag shells in an oil bath. The method can prepare not only triangular Au@Ag core-shells, but also nanoplates, octahedrons and decahedrons depending on the shapes of the Au seeds. In addition, these Ag shell shapes are significantly different from those prepared in EG by microwave heating from the same $\mathrm{Au}$ seeds. The reason is the favorable facets of Ag nanostructures produced in EG and DMF are different, which has been discussed before. Using the microwave-polyol method, their group also prepared Au@ Ag core-shell icosahedrons [105]. In 2012, they explored the growth mechanism of Au@Ag core-shell octahedra and decahedra using a similar method [106]. They argued that nanocrystal growth process mainly depends on the way of heating. Uniform Au@Ag core-shell octahedra and decahedra can be obtained under oil bath heating, while under fast microwave heating the Ag shell is not uniform. Above all, the microwave-polyol method provides a new and facile path for synthesize various $\mathrm{Au} @ \mathrm{Ag}$ core-shell nanostructures.

In addition to these $\mathrm{Au} @ \mathrm{Ag}$ core-shell nanostructures above, Ag nanocubes also receive much attention. Fan et al. [107] synthesized Au@ Ag core-shell nanocubes by using Au octahedra as seeds in high yield for the first time. Later on, Ma et al. [108] described a simple method for preparing Au@Ag core-shell nanocubes from Au nanopheres. In this case, the edge lengths of the Ag nanobox can be finely tuned from 13 to $50 \mathrm{~nm}$ by controlling the amount of $\mathrm{AgNO}_{3}$ or $\mathrm{Au}$ seeds which were close to the calculated results, and the thickness of $\mathrm{Ag}$ shell can be controlled precisely from 1.2 to $20 \mathrm{~nm}$ because the seeds are isotropic and have uniform size. Moreover, they found that the effect of CTAC as capping agent on the formation of $\mathrm{Au} @ \mathrm{Ag}$ core-shell nanocubes was better than that of CATB. 
Figure 11. Schematic crystal structures of the Au cores and Au@Ag nanocrystals prepared in DMF by an oil-bath heating (right side) and in EG by a MW heating (left side) (reprinted with permission from [94]. Copyright (2008) American Chemical Society).

(a)

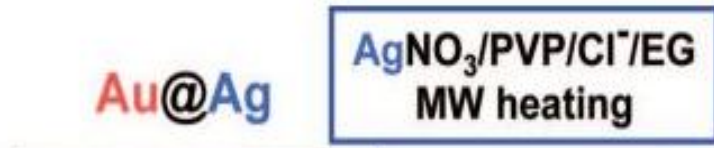

\section{$\mathrm{AgNO}_{3} / \mathrm{PVP} / \mathrm{DMF} /$ Oil-bath heating}

Au@Ag

(b)

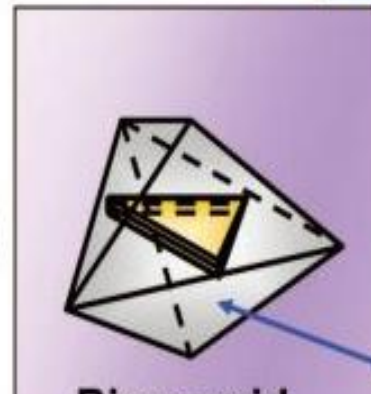

(c)
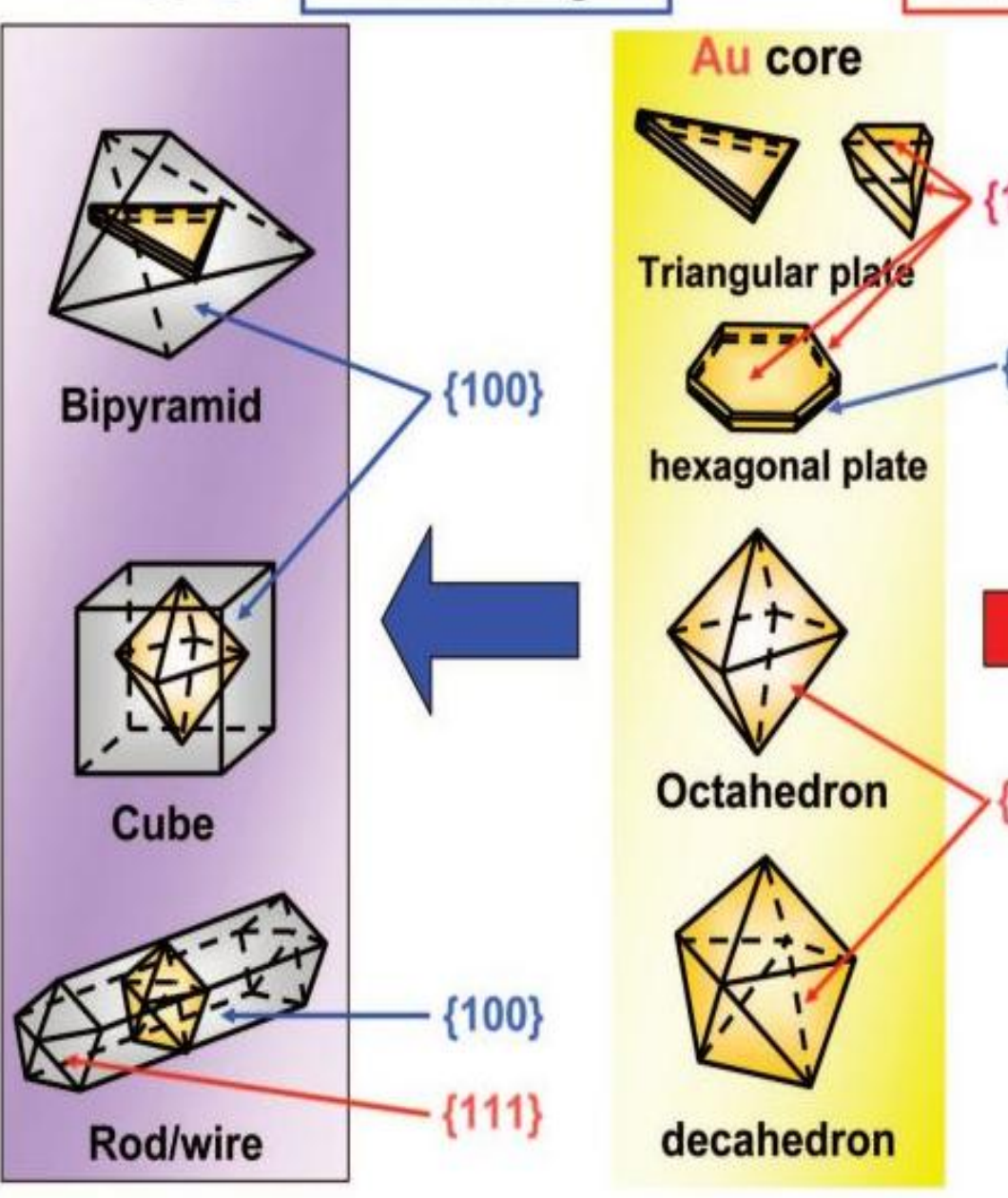

Au core 
Table 1. Comparison of physical constants between the core metal and the shell metal in various combinations of binary metal nanocrystals (reprinted with permission from [107]. Copyright (2008) American Chemical Society).

\begin{tabular}{ccccc}
\hline Core-Shell & $\begin{array}{c}\text { Atomic Radius } \\
\mathbf{r}_{\text {core }} \text { vs } \mathbf{r}_{\text {shell }}\end{array}$ & $\begin{array}{c}\text { Bond Dissociation } \\
\text { Energies }\end{array}$ & $\begin{array}{c}\text { Electronegativiy } \\
\text { (Paulings) }\end{array}$ & $\begin{array}{c}\text { Experimental Observation } \\
\text { of Epitaxial Growth }\end{array}$ \\
\hline $\mathrm{Pt} @ \mathrm{Au}$ & small & high & low & no \\
$\mathrm{Pt} @ \mathrm{Ag}$ & small & high & high & no report \\
$\mathrm{Pt} @ \mathrm{Pd}$ & large & high & high & yes \\
$\mathrm{Au} @ \mathrm{Pd}$ & large & high & high & yes \\
$\mathrm{Au} @ \mathrm{Ag}$ & equal & high & high & yes \\
$\mathrm{Au} @ \mathrm{Pt}$ & large & low & high & no \\
$\mathrm{Ag} @ \mathrm{Pd}$ & large & high & low & no \\
$\mathrm{Ag} @ \mathrm{Au}$ & equal & low & low & no \\
$\mathrm{Ag} @ \mathrm{Pt}$ & large & low & low & no \\
$\mathrm{Pd} @ \mathrm{Au}$ & small & low & low & no \\
$\mathrm{Pd} @ \mathrm{Ag}$ & small & low & high & no report \\
$\mathrm{Pd} @ \mathrm{Pt}$ & small & low & low & no report \\
\hline
\end{tabular}

\section{Application}

In the past decades, silver nanoparticles have been applied to many areas because of their excellent optical properties. The three methods introduced in this essay can not only control the shapes and sizes of silver nanostructures well, but also their LSPR properties, leading to more potential applications.

Figure 12. (a) Curves a-c plot the relationship between $\mid$ Emax $\mid$ and the wave-length for long nano-flags ( $\mathrm{L}=2 \mathrm{um}$ ) with $\mathrm{W}=150,200$, and $275 \mathrm{~nm}$, respectively; (b) Curves a-c show the relationship between $\mid$ Emax $\mid$ and the wavelength for long nano-flags (L = $2 \mathrm{um}$ ) with $\mathrm{W}=210,250$, and $310 \mathrm{~nm}$, respectively. The inset in (b) illustrates the position of the focused incident light spot in the simulation model for the excitation of the long nano-flags (reprinted with permission from [112]. Copyright (2012) AIP Publishing LLC).

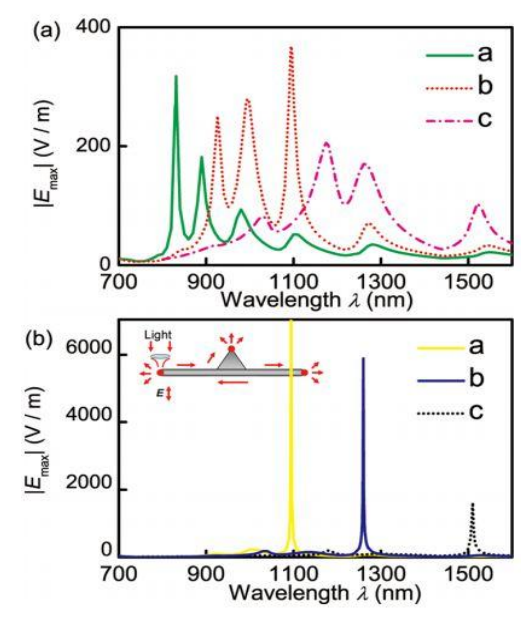

As mentioned in Section 1.1, Tsuji et al. have synthesized silver nanoflags which combine a nanowires and a triangular nanoplate by a double reductant method as shown in Figure 4. Zhang et al. [112] studied 
the plasmonic properties of silver nanoflags by theoretical simulation. In their simulations they investigate the spectral properties of silver nanoflags of different widths. It can be seen from Figure 12a that resonance spectra of silver nanoflags induced by SPP mode depends on the width of the nanoplate. When the width is tuned some special values as shown in Figure 12b, the spectrum has a single resonance band with an ultra-narrow bandwidth and significant electric-field enhancement. Therefore such a nanoflag can be used in spacer-based nanolasers. The plasmonic properties of porous of $\mathrm{Au}-\mathrm{Ag}$ alloy nanocages were studied by the finite element method [113]. The results show that the plasmon mode can be tunable by changing the surface porosity. When a Au nanobox transforms into a nanocage, the plasmon mode shifts red, which means that larger surface porosity causes more redshift. The simulation result is demonstrated by Zhang et al. [73]. They prepared Au-Ag alloy nanoboxes by the $\mathrm{H}_{2} \mathrm{O}_{2}$ etching technique. In Figure 13 we see the absorption spectra of Au-Ag alloy nanoboxes (black line) and nanocages (red line). It can be seen that LSPR peaks of Au-Ag nanoboxes are red-shifted from 460, 520, 675 and $745 \mathrm{~nm}$ to 1210, 925, 790 and $758 \mathrm{~nm}$, respectively, after the treatment with excess $\mathrm{H}_{2} \mathrm{O}_{2}$. Because the scattering and absorption of $\mathrm{Au}$ nanocages can be tailored by controlling the size and porosity, Chen et al. [114] functionalized Au nanocages with an antibody to cancer cells. In addition, they found Au nanocages have a photothermal effect when selectively attached to cancer cells, killing them by inducing localized heating. The remarkable LSPR properties of Au nanocages make them promising in the biomedical area.

Figure 13. UV-vis-NIR spectra of the samples that correspond to the Au-Ag alloy nanoboxes and nanocages shown in Figure 5. The spectra in black are for the starting Au-Ag nanoboxes and the spectra in red are for the resulting Au-based nanocages after a reaction with an excess amount of $\mathrm{H}_{2} \mathrm{O}_{2}$. For the nanoboxes, the LSPR peaks were at (A) 460; (B) 520; (C) 675; and (D) $745 \mathrm{~nm}$. The spectra were normalized to unity. For the nanocages, the LSPR peak was red-shifted to the near-infrared region for the first two samples of nanocages due to their extremely thin walls. The spectra were normalized by dividing the same factor to the corresponding spectra of the nanobox (reprinted with permission from [73]. Copyright (2010) American Chemical Society).
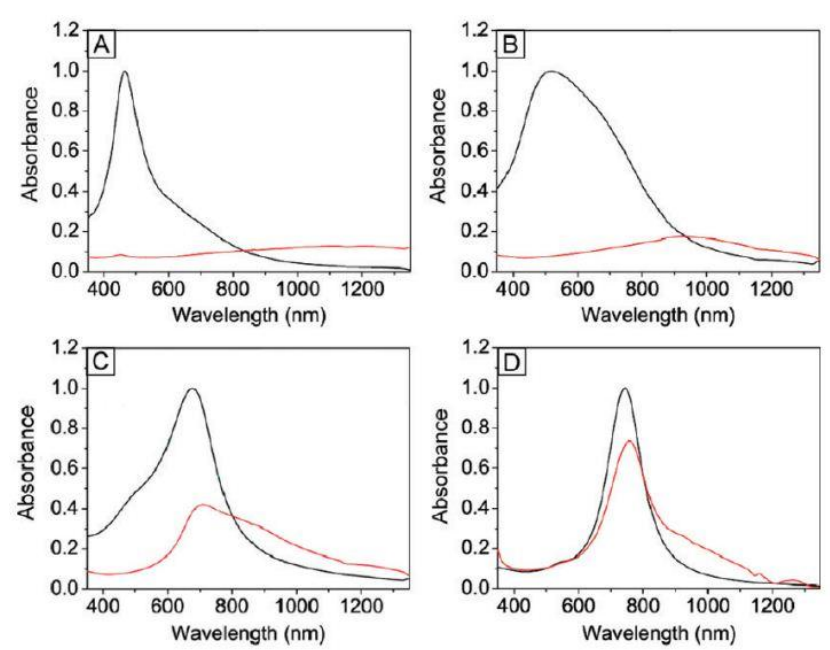

$\mathrm{Au} @ \mathrm{Ag}$ core-shell nanostructures have attracted considerable attention because of their improved properties compared with silver nanostructures or gold nanostructures, especially optical properties, which allows them to be used as SERS substrates. Generally, SERS substrates should be sensitive, stable 
and rapid. Khlebtsov et al. [115] investigated the SERS spectra of rhodamine 6G (R6G) by using Au@Ag core-shell nanorods as substrate. NR-0, NR-1 and NR-2 represent gold nanorods, Au@Ag core-shell nanorods with $1.05 \mathrm{~nm}$ and $2 \mathrm{~nm}$ silver shells, respectively. It can be seen from Figure 14 that the Raman signal of R6G with NR-1 was much higher than NR-0, and with the increase of thickness of silver shells, the intensity enhanced. They assumed that the SERS enhancement of Au@Ag core-shell nanorods was related to the electromagnetic field distribution. To confirm their assumption, they resorted to three-dimensional finite-difference time-domain (FDTD) simulations, which indicated that the hotspots near the end-to-end and end-to-side nanoparticle contacts caused the SERS enhancement of Au@Ag core-shell nanorods. We previously reported that gold nanoparticle thin films can be used as sensitive SERS substrates, because hot spots formed in the narrow gaps regions between neighboring nanoparticles can enhance the Roman signal [11]. This opinion was also proved by Costa et al. [116]. They prepared $\mathrm{Au} @ \mathrm{Ag}$ core-shell nanotubes with hotspots in the surface, which exhibited more excellent SERS properties than silver nanowires. It is well known that silver nanoparticles are easy to oxidize, so another challenge is how to keep the SERS substrate stable. Gute et al. [117] found that when silver dendrite was coated by gold and was used as SERS substrate, the stability was improved with a slight decrease of intensity of the SERS enhancement. Therefore, Au@Ag core-shell nanostructures can serve as ideal SERS substrates for chemical and biological detection processes.

Figure 14. SERS spectra of R6G $(1 \mu \mathrm{L}, 80 \mu \mathrm{M})$ deposited with NR-0 (1), NR-1 (2), and NR-3 (3) rods at a Au concentration of $14 \mathrm{~g} / \mathrm{L}$ (reprinted with permission from [115]. Copyright (2013) American Chemical Society).

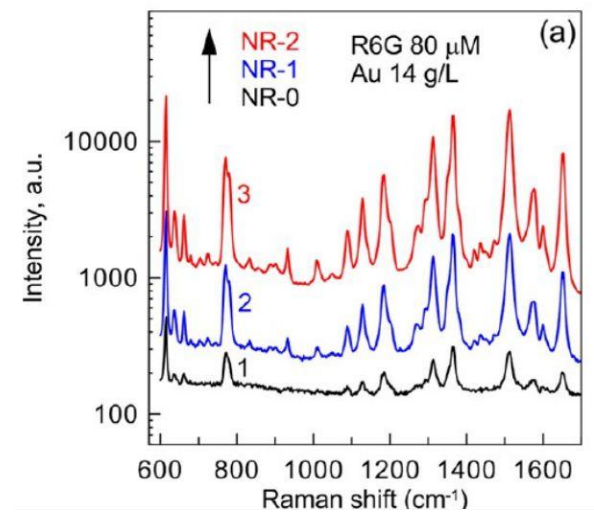

Metal ions do not have Raman signals, which have to be detected by indirect methods leading to inefficiency. To solve the problem, many efforts have been devoted to find ways to detect metal ions (such as $\mathrm{Hg}^{2+}, \mathrm{Cu}^{2+}$ ) in a simple, rapid and ultrasensitive way [118-120]. However, we found that the detection limitation of $\mathrm{Hg}^{2+}$ was $10^{-12} \mathrm{M}$ by using a single-metallic nanostructures as sensor. To further decrease the detection limitation, Du et al. [121] applied a SERS chip constituted of Au@Ag core-shell nanoparticles with an organic ligand (Dpy) in the detection of $\mathrm{Hg}^{2+}$ as shown in Figure 15a. When the water droplet containing $\mathrm{Hg}^{2+}$ was added onto the chip, the Raman signals of Dpy obviously quenched due to the formation of $\mathrm{Hg}^{2+}$-Dpy complex. The results in Figure $15 \mathrm{~b}$ show that even $10^{-14} \mathrm{M} \mathrm{Hg}^{2+}$ can been detected due to the more excellent SERS properties of Au@Ag core-shell nanostructures. In addition, this approach just needs $4 \mathrm{~min}$ and $20 \mu \mathrm{L}$ of sample. Therefore, Au@ Ag core-shell nanostructures can be used for the ultrasensitive detection of trace $\mathrm{Hg}^{2+}$. Similar to $\mathrm{Hg}^{2+}, \mathrm{Cu}^{2+}$ has paramagnetic properties 
which can transfer electrons or energy resulting in photoluminescence (PL) quenching of $\mathrm{Au} @ \mathrm{Ag}$ core-shell nanoparticles. Gui et al. [122] first employed Au@Ag core-shell nanoparticles in the development of a PL sensor for the detection of $\mathrm{Cu}^{2+}$. As the concentration of $\mathrm{Cu}^{2+}$ increased, the PL spectra of $\mathrm{Au} @ \mathrm{Ag}$ core-shell nanoparticles dropped dramatically, so we can analyze $\mathrm{Cu}^{2+}$ according to the intensity of PL spectra. In addition to metallic ions analyses, biomolecules and organic molecules have attracted much attention. Panfilova et al. [123] first studied the application of multicolor Au@ Ag core-shell nanoparticles in a multiplexed solid-phase dot immunoassay. During the transformation process from silver nanocubes to Au@Ag core-shell nanoparticles, the color varied from yellow to blue with the shift of the SPR peak from 450 to $700 \mathrm{~nm}$. Then different color nanoparticles were conjugated with different immuno gamma globulin molecular probes. As a result, when these colorless anti-rat rabbit antibodies were stained by functional molecular probes, they showed the corresponding colors, which can be regarded as detection basis of immunoassay. Liu et al. [124] reported the shell thickness-dependent Raman enhancement of Au@Ag core-shell nanoparticles for the identification and detection of pesticide residues at various fruit peels, where it was first proposed that the huge Raman enhancement was contributed by individual Au@Ag NPs rather than aggregated Au@Ag core-shell nanoparticles with hotspots among the neighboring NPs. Figure 16 illustrates a schematic drawing (A) for the direct detection of pesticide residues at fruit peels by SERS spectroscopy using Au@ Ag NPs as Raman amplifier, and the SERS spectra of (B) apple and (C) mango peels spiked with thiram by the enhancement of $\mathrm{Au} @ \mathrm{Ag}$ NPs colloid that was cast onto the surfaces of the fruit peels.

Figure 15. (A) Schematic drawing for direct detection of $\mathrm{Hg}^{2+}$ with the SERS chip fabricated by the assembly of Au@Ag NPs on a silicon wafer; (B) Evolution of SERS spectra of Dpy with the addition of anaqueous $\mathrm{Hg}^{2+}$ droplet. The inset is the linear correlation of Raman intensity (at $1614 \mathrm{~cm}^{-1}$ ) with the logarithm of $\mathrm{Hg}^{2+}$ concentrations from $1.0 \times 10^{-14}$ to $1.0 \times 10^{-10} \mathrm{M}$ (reprinted with permission from [121]. Copyright (2013) American Chemical Society).
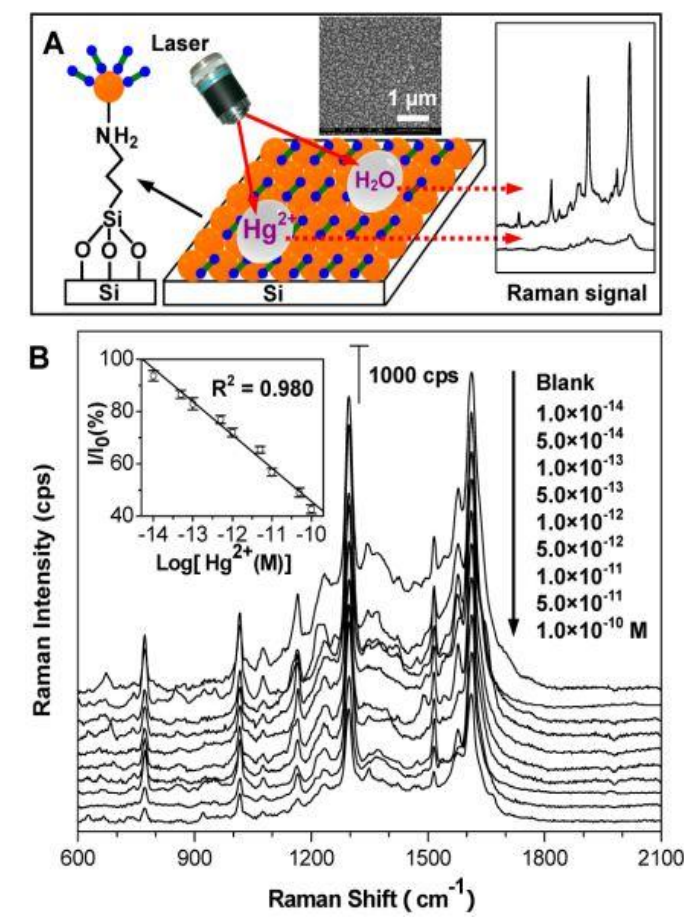
In the research of Zheng et al. [125], Au@Ag core-shell bipyramids was used for a fast and reproducible determination of thiram, which provided satisfactory results for the dectection of thiram in environmental water samples. Furthermore, bifunctional core-shell particles have multiple functions. For example, FePt@Ag core-shell nanostructures not only have excellent SERS properties, but also high saturation magnetization [126]. Although Fe and Pt belong to the transition-metals which have rather weak SERS signals [127], they can achieve high SERS activity by borrowing SERS activity from silver or gold nanostructures which can create long-range effect of the very strong electromagnetic field to enhance the Raman scattering of adsorbents. The magnetic-plasmonic FePt@Ag NPs have potential applications in biomedicine.

Figure 16. (A) Schematic drawing for the direct detection of pesticide residues at fruit peels by the SERS spectroscopy using Au@Ag NPs as Raman amplifier, and the SERS spectra of (B) apple and (C) mango peels spiked with thiram by the enhancement of Au@Ag NPs colloid that was cast onto the surfaces of the fruit peels. All Raman spectra were recorded with a $532 \mathrm{~nm}$ laser with $5 \mathrm{~mW}$ power and 10x objectives (reprinted with permission from [124]. Copyright (2012) American Chemical Society).

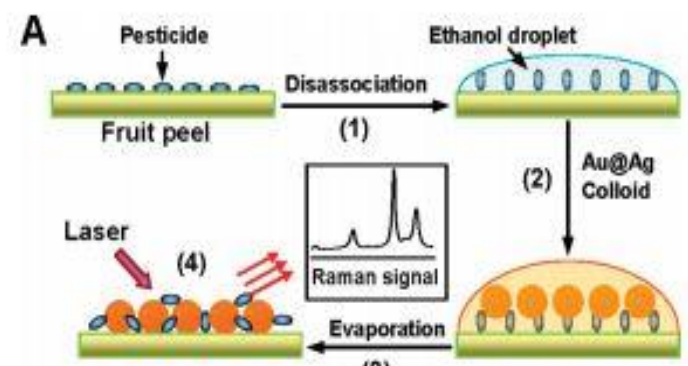

(3)

B

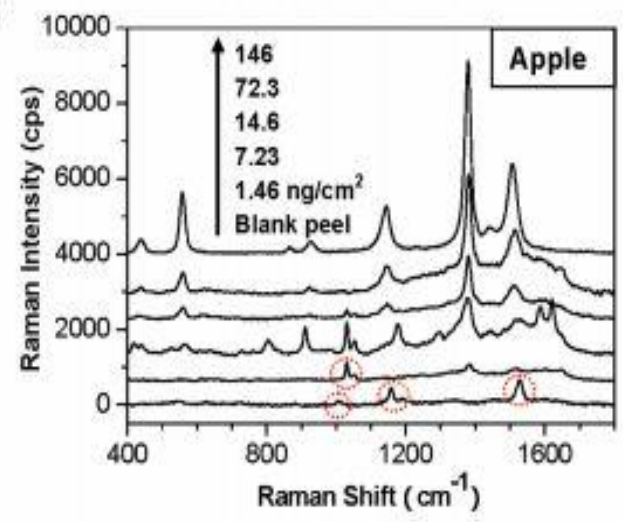

C

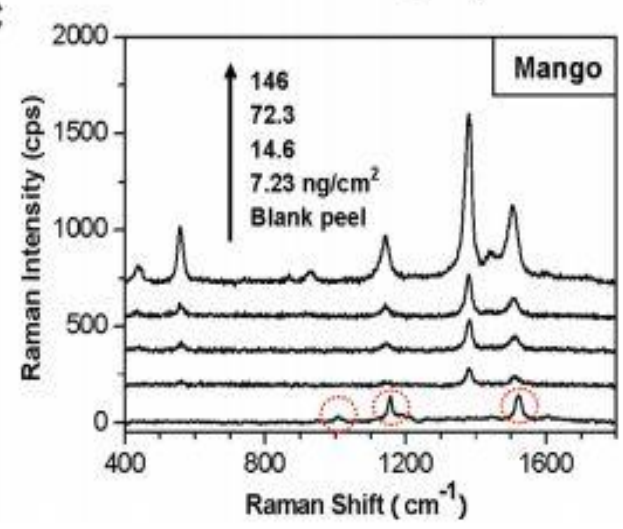




\section{Conclusions}

In this review, we present double reductant methods, etching techniques and construction of core-shell nanostructures routes which can synthesize novel shape-controlled silver nanostructures. Various silver nanostructures have been prepared by using the three methods. The double reductant method takes full advantage of different favorable facets of nanostructures produced in different reductants. In this case, complex nanostructures which are not easily prepared by one-step methods can be prepared in high yield with mono-dispersed sizes. The etching technique can synthesize hollow nanostructures with tunable silver shell thickness which can be used for controlling their LSPR. Moreover, etching technique can also increase the roughness of the surface of silver nanostructures, significantly increasing SERS enhancement and LSPR effect. The construction of core-shell nanostructures can not only control their shapes and sizes well, but also exhibit more excellent optical properties than that of individual metal nanostructures. Finally, we introduce applications of silver nanostructures produced by the three methods. Because of their excellent optical properties, such as LSPR properties and SERS effect, these silver nanostructures have potential applications for the development of plasmonic nanodevices and detection.

\section{Author Contributions}

Tong Zhang and Yuan-Jun Song drafted the main parts of manuscript. Xiao-Yang Zhang and Jing-Yuan $\mathrm{Wu}$ participated in the draft preparation. All authors read and approved the final manuscript.

\section{Conflicts of Interest}

The authors declare no conflict of interest.

\section{Acknowledgments}

This work is supported by NSFC under grant number 61307066, Doctoral Fund of Ministry of Education of China under grant number 20110092110016 and 20130092120024, Natural Science Foundation of Jiangsu Province under grant number BK20130630, the National Basic Research Program of China (973 Program) under grant number 2011CB302004 and the Foundation of Key Laboratory of Micro-Inertial Instrument and Advanced Navigation Technology, Ministry of Education, China under Grant No. 201204.

\section{References}

1. Butun, S.; Sahiner, N. A versatile hydrogel template for metal nano particle preparation and their use in catalysis. Polymer 2011, 52, 4834-4840.

2. Harish, S.; Sabarinathan, R.; Joseph, J.; Phani, K.L.N. Role of pH in the synthesis of 3-aminopropyl trimethoxysilane stabilized colloidal gold/silver and their alloy sols and their application to catalysis. Mater. Chem. Phys. 2011, 127, 203-207.

3. Yang, J.; Wang, Z.; Zong, S.; Song, C.; Zhang, R.; Cui, Y. Distinguishing breast cancer cells using surface-enhanced Raman scattering. Anal. Bioanal. Chem. 2012, 402, 1093-1100. 
4. Alivisatos, P. The use of nanocrystals in biological detection. Nat. Biotechnol. 2004, 22, 47-52.

5. Hong, Y.; Huh, Y.M.; Yoon, D.S.; Yang, J. Nanobiosensors based on localized surface plasmon resonance for biomarker detection. J. Nanomater. 2012, 2012, 1-13.

6. Tripp, R.A.; Dluhy, R.A.; Zhao, Y. Novel nanostructures for SERS biosensing. Nano Today 2008, 3, 31-37.

7. Samanta, A.; Maiti, K.K.; Soh, K.S.; Liao, X.; Vendrell, M.; Dinish, U.S.; Yun, S.W.; Bhuvaneswari, R.; Kim, H.; Rautela, S.; et al. Ultrasensitive near-infrared Raman reporters for SERS-based in vivo cancer detection. Angew. Chem. Int. Ed. Engl. 2011, 50, 6089-6092.

8. Kumar, A.; Boruah, B.M.; Liang, X.-J. Gold nanoparticles: Promising nanomaterials for the diagnosis of cancer and HIV/AIDS. J. Nanomater. 2011, 2011, 1-17.

9. Cao, Y.; Li, D.; Jiang, F.; Yang, Y.; Huang, Z. Engineering metal nanostructure for SERS application. J. Nanomater. 2013, 2013, 1-12.

10. Botta, R.; Upender, G.; Sathyavathi, R.; Narayana Rao, D.; Bansal, C. Silver nanoclusters films for single molecule detection using Surface Enhanced Raman Scattering (SERS). Mater. Chem. Phys. 2013, 137, 699-703.

11. Zhu, S.Q.; Zhang, T.; Guo, X.L.; Wang, Q.L.; Liu, X.F.; Zhang, X.Y. Gold nanoparticle thin films fabricated by electrophoretic deposition method for highly sensitive SERS application. Nanoscale Res. Lett. 2012, 7, 1-7.

12. Zhang, X.Y.; Hu, A.M.; Zhang, T.; Lei, W.; Xue, X.J.; Zhou, Y.H.; Duley, W.W. Self-assembly of large-scale and ultrathin silver nanoplate films with tunable plasmon resonance properties. ACS Nano 2011, 5, 9082-9092.

13. Cobley, C.M.; Skrabalak, S.E.; Campbell, D.J.; Xia, Y. Shape-Controlled synthesis of silver nanoparticles for plasmonic and sensing applications. Plasmonics 2009, 4, 171-179.

14. Ray, P.C. Size and shape dependent second order nonlinear optical properties of nanomaterials and their application in biological and chemical sensing. Chem. Rev. 2010, 110, 5332-5365.

15. Pietrobon, B.; Kitaev, V. Photochemical synthesis of monodisperse size-controlled silver decahedral nanoparticles and their remarkable optical properties. Chem. Mater. 2008, 20, 5186-5190.

16. Wiley, B.; Sun, Y.G.; Xia, Y.N. Polyol synthesis of silver nanostructures: Control of product morphology with Fe(II) or Fe(III) species. Langmuir 2005, 21, 8077-8080.

17. Wiley, B.; Sun, Y.G.; Chen, J.Y.; Cang, H.; Li, Z.Y.; Li, X.D.; Xia, Y.N. Shape-controlled synthesis of silver and gold nanostructures. Mrs Bull. 2005, 30, 356-361.

18. Sun, Y.; Xia, Y. Shape-controlled synthesis of gold and silver nanoparticles. Science 2002, 298, 2176-2179.

19. Wiley, B.; Sun, Y.G.; Mayers, B.; Xia, Y.N. Shape-controlled synthesis of metal nanostructures: The case of silver. Chem.-A Eur. J. 2005, 11, 454-463.

20. Xia, Y.; Xiong, Y.; Lim, B.; Skrabalak, S.E. Shape-controlled synthesis of metal nanocrystals: simple chemistry meets complex physics? Angew. Chem. Int. Ed. Engl. 2009, 48, 60-103.

21. Wiley, B.; Herricks, T.; Sun, Y.G.; Xia, Y.N. Polyol synthesis of silver nanoparticles: Use of chloride and oxygen to promote the formation of single-crystal, truncated cubes and tetrahedrons. Nano Lett. 2004, 4, 1733-1739.

22. Sun, Y.G.; Xia, Y.N. Large-scale synthesis of uniform silver nanowires through a soft, self-seeding, polyol process. Adv. Mater. 2002, 14, 833-837. 
23. Sun, Y.G.; Mayers, B.; Herricks, T.; Xia, Y.N. Polyol synthesis of uniform silver nanowires: A plausible growth mechanism and the supporting evidence. Nano Lett. 2003, 3, 955-960.

24. Sun, Y.G.; Gates, B.; Mayers, B.; Xia, Y.N. Crystalline silver nanowires by soft solution processing. Nano Lett. 2002, 2, 165-168.

25. Song, Y.J.; Wang, M.L.; Zhang, X.Y.; Wu, J.Y.; Zhang, T. Investigation on the role of the molecular weight of polyvinyl pyrrolidone in the shape control of high-yield silver nanospheres and nanowires. Nanoscale Res. Lett. 2014, 9, 1-8.

26. Wiley, B.J.; Im, S.H.; Li, Z.Y.; McLellan, J.; Siekkinen, A.; Xia, Y.N. Maneuvering the surface plasmon resonance of silver nanostructures through shape-controlled synthesis. J. Phys. Chem. B 2006, 110, 15666-15675.

27. Junior, A.M.; de Oliveira, H.P.M.; Gehlen, M.H. Preparation of silver nanoprisms using poly(N-vinyl-2-pyrrolidone) as a colloid-stabilizing agent and the effect of silver nanoparticles on the photophysical properties of cationic dyes. Photochem. Photobiol. 2003, 2, 921-925.

28. Jin, R.C.; Cao, Y.C.; Hao, E.C.; Metraux, G.S.; Schatz, G.C.; Mirkin, C.A. Controlling anisotropic nanoparticle growth through plasmon excitation. Nature 2003, 425, 487-490.

29. Lee, S.Y.; Jeon, H.C.; Yang, S.-M. Unconventional methods for fabricating nanostructures toward high-fidelity sensors. J. Mater. Chem. 2012, 22, 5900-5913.

30. Jones, M.R.; Osberg, K.D.; Macfarlane, R.J.; Langille, M.R.; Mirkin, C.A. Templated techniques for the synthesis and assembly of plasmonic nanostructures. Chem. Rev. 2011, 111, 3736-3827.

31. Yu, J.Y.; Schreiner, S.; Vaska, L. Homogeneous catalytic production of hydrogen and other molecules from water Dmf solutions. Inorg. Chim. Acta 1990, 170, 145-147.

32. Pastoriza-Santos, I.; Liz-Marzán, L.M. Formation and stabilization of silver nanoparticles through reduction by N, N-dimethylformamide. Langmuir 1999, 15, 948-951.

33. Pastoriza-Santos, I.; Liz-Marzán, L.M. Formation of PVP-protected metal nanoparticles in DMF. Langmuir 2002, 18, 2888-2894.

34. Pastoriza-Santos, I.; Liz-Marzán, L.M. Synthesis of silver nanoprisms in DMF. Nano Lett. 2002, 2, 903-905.

35. Pastoriza-Santos, I.; Liz-Marzán, L.M. N,N-Dimethylformamide as a reaction medium for metal nanoparticle synthesis. Adv. Funct. Mater. 2009, 19, 679-688.

36. Giersig, M.; Pastoriza-Santos, I.; Liz-Marzán, L.M. Evidence of an aggregative mechanism during the formation of silver nanowires in $N, N$-dimethylformamideElectronic supplementary information (ESI) available: TEM micrographs showing early (left) and late (right) stages during the formation of Ag nanowires. J. Mater. Chem. 2004, 14, 607.

37. Gao, Y.; Jiang, P.; Song, L.; Wang, J.X.; Liu, L.F.; Liu, D.F.; Xiang, Y.J.; Zhang, Z.X.; Zhao, X.W.; Dou, X.Y.; et al. Studies on silver nanodecahedrons synthesized by PVP-assisted N,N-dimethylformamide (DMF) reduction. J. Cryst. Growth 2006, 289, 376-380.

38. Tsuji, M.; Ogino, M.; Matsuo, R.; Kumagae, H.; Hikino, S.; Kim, T.; Yoon, S.-H. Stepwise growth of decahedral and icosahedral silver nanocrystals in DMF. Cryst. Growth Des. 2010, 10, 296-301.

39. Lu, Q.; Lee, K.J.; Lee, K.B.; Kim, H.T.; Lee, J.; Myung, N.V.; Choa, Y.H. Investigation of shape controlled silver nanoplates by a solvothermal process. J. Colloid Interface Sci. 2010, 342, 8-17. 
40. Siekkinen, A.R.; McLellan, J.M.; Chen, J.; Xia, Y. Rapid synthesis of small silver nanocubes by mediating polyol reduction with a trace amount of sodium sulfide or sodium hydrosulfide. Chem. Phys. Lett. 2006, 432, 491-496.

41. Wiley, B.; Sun, Y.G.; Xia, Y.N. Synthesis of silver nanostructures with controlled shapes and properties. Acc. Chem. Res. 2007, 40, 1067-1076.

42. Tsuji, M.; Maeda, Y.; Hikino, S.; Kumagae, H.; Matsunaga, M.; Tang, X.-L.; Matsuo, R.; Ogino, M.; Jiang, P. Shape evolution of octahedral and triangular platelike silver nanocrystals from cubic and right bipyramidal seeds in DMF. Cryst. Growth Des. 2009, 9, 4700-4705.

43. Tsuji, M.; Tang, X.; Matsunaga, M.; Maeda, Y.; Watanabe, M. Shape evolution of flag types of silver nanostructures from nanorod seeds in PVP-assisted DMF solution. Cryst. Growth Des. 2010, 10, 5238-5243.

44. Zhang, Y.; Yang, P.; Zhang, L. Size- and shape-tunable silver nanoparticles created through facile aqueous synthesis. J. Nanopart. Res. 2012, 15, 1-10.

45. Zhang, X.Y.; Zhang, T.; Zhu, S.Q.; Wang, L.D.; Liu, X.F.; Wang, Q.L.; Song, Y.J. Fabrication and spectroscopic investigation of branched silver nanowires and nanomeshworks. Nanoscale Res. Lett. 2012, 7,596.

46. Wojtysiak, S.; Kudelski, A. Influence of oxygen on the process of formation of silver nanoparticles during citrate/borohydride synthesis of silver sols. Colloids Surf. A: Physicochem. Eng. Asp. 2012, $410,45-51$.

47. Yi, Z.; Xu, X.; Wu, X.; Chen, C.; Li, X.; Luo, B.; Luo, J.; Jiang, X.; Wu, W.; Yi, Y.; Tang, Y. Silver nanoplates: Controlled preparation, self-assembly, and applications in surface-enhanced Raman scattering. Appl. Phys. A 2012, 110, 335-342.

48. Yang, J.; Zhang, Q.; Lee, J.Y.; Too, H.P. Dissolution-recrystallization mechanism for the conversion of silver nanospheres to triangular nanoplates. J. Colloid Interface Sci. 2007, 308, 157-161.

49. Fukuyo, T.; Imai, H. Morphological evolution of silver crystals produced by reduction with ascorbic acid. J. Cryst. Growth 2002, 241, 193-199.

50. Zheng, X.; Zhu, L.; Yan, A.; Wang, X.; Xie, Y. Controlling synthesis of silver nanowires and dendrites in mixed surfactant solutions. J. Colloid Interface Sci. 2003, 268, 357-361.

51. Lou, X.W.; Yuan, C.L.; Archer, L.A. An unusual example of hyperbranched metal nanocrystals and their shape evolution. Chem. Mater. 2006, 18, 3921-3923.

52. Wang, Y.L.; Camargo, P.H.C.; Skrabalak, S.E.; Gu, H.C.; Xia, Y.N. A facile, water-based synthesis of highly branched nanostructures of silver. Langmuir 2008, 24, 12042-12046.

53. Banfield, J.F. Aggregation-based crystal growth and microstructure development in natural iron oxyhydroxide biomineralization products. Science 2000, 289, 751-754.

54. Khan, Z.; Singh, T.; Hussain, J.I.; Obaid, A.Y.; Al-Thabaiti, S.A.; El-Mossalamy, E.H. Starch-directed green synthesis, characterization and morphology of silver nanoparticles. Colloids Surf. B Biointerfaces 2013, 102, 578-584.

55. Yang, J.C.; Chen, C.-H.; Wu, R.J. Facile growth of silver crystals with greatly varied morphologies by PEO-PPO-PEO tri-block copolymers. Cryst. Eng. Comm. 2012, 14, 2871-2878.

56. Chen, B.; Jiao, X.; Chen, D. Size-controlled and size-designed synthesis of nano/submicrometer Ag particles. Cryst. Growth Des. 2010, 10, 3378-3386. 
57. Samanta, S.; Sarkar, P.; Pyne, S.; Sahoo, G.P.; Misra, A. Synthesis of silver nanodiscs and triangular nanoplates in PVP matrix: Photophysical study and simulation of UV-vis extinction spectra using DDA method. J. Mol. Liq. 2012, 165, 21-26.

58. Levinstein, H.J.; Robinson, W.H. Etch Pits at dislocations in silver single crystals. J. Appl. Phys. 1962, 33, 3149-3152.

59. Som, T.; Karmakar, B. Core-shell Au-Ag nanoparticles in dielectric nanocomposites with plasmon-enhanced fluorescence: A new paradigm in antimony glasses. Nano Res. 2009, 2, $607-616$.

60. Jin, R.; Cao, Y.; Mirkin, C.A.; Kelly, K.L.; Schatz, G.C.; Zheng, J.G. Photoinduced conversion of silver nanospheres to nanoprisms. Science 2001, 294, 1901-1903.

61. Xue, C.; Metraux, G.S.; Millstone, J.E.; Mirkin, C.A. Mechanistic study of photomediated triangular silver nanoprism growth. J. Am. Chem. Soc. 2008, 130, 8337-8344.

62. Xue, C.; Mirkin, C.A. pH-switchable silver nanoprism growth pathways. Angew. Chem.-Int. Ed. 2007, 46, 2036-2038.

63. Millstone, J.E.; Métraux, G.S.; Mirkin, C.A. Controlling the edge length of gold nanoprisms via a seed-mediated approach. Adv. Funct. Mater. 2006, 16, 1209-1214.

64. Métraux, G.S.; Mirkin, C.A. Rapid thermal synthesis of silver nanoprisms with chemically tailorable thickness. Adv. Mater. 2005, 17, 412-415.

65. Zhang, Q.; Li, N.; Goebl, J.; Lu, Z.; Yin, Y. A systematic study of the synthesis of silver nanoplates: is citrate a "magic" reagent? J. Am. Chem. Soc. 2011, 133, 18931-18939.

66. Tsuji, M.; Gomi, S.; Maeda, Y.; Matsunaga, M.; Hikino, S.; Uto, K.; Tsuji, T.; Kawazumi, H. Rapid transformation from spherical nanoparticles, nanorods, cubes, or bipyramids to triangular prisms of silver with PVP, citrate, and $\mathrm{H}_{2} \mathrm{O}_{2}$. Langmuir 2012, 28, 8845-8861.

67. Sun, Y.; Mayers, B.T.; Xia, Y. Template-engaged replacement reaction: A one-step approach to the large-scale synthesis of metal nanostructures with hollow interiors. Nano Lett. 2002, 2, $481-485$.

68. Chien, Y.H.; Tsai, M.F.; Shanmugam, V.; Sardar, K.; Huang, C.L.; Yeh, C.S. Escape from the destruction of the galvanic replacement reaction for solid --> hollow --> solid conversion process in one pot reaction. Nanoscale 2013, 5, 3863-3871.

69. Sun, Y.G.; Xia, Y.N. Mechanistic study on the replacement reaction between silver nanostructures and chloroauric acid in aqueous medium. J. Am. Chem. Soc. 2004, 126, 3892-3901.

70. Skrabalak, S.E.; Chen, J.; Sun, Y.; Lu, X.; Au, L.; Cobley, C.M.; Xia, Y. Gold nanocages: Synthesis, properties, and applications. Acc. Chem. Res. 2008, 41, 1587-1595.

71. Shahjamali, M.M.; Martinsson, E.; Marcello, W.; Yin, L.S.; Liedberg, B.; Boey, F.; Xue, C. Edge gold-coated silver nanoprism [Ag@ (Au nanoframe)] for $\mathrm{H}_{2} \mathrm{O}_{2}$ detection. In Proceedings of the Third Asia Pacific Optical Sensors Conference, Sydney, Australia, 2012; Volume 8351.

72. Sun, Y.; Wiley, B.; Li, Z.Y.; Xia, Y. Synthesis and optical properties of nanorattles and multiple-walled nanoshells/nanotubes made of metal alloys. J. Am. Chem. Soc. 2004, 126, 9399-9406.

73. Zhang, Q.; Cobley, C.M.; Zeng, J.; Wen, L.P.; Chen, J.Y.; Xia, Y.N. Dissolving Ag from Au-Ag alloy nanoboxes with $\mathrm{H}_{2} \mathrm{O}_{2}$ : A method for both tailoring the optical properties and measuring the $\mathrm{H}_{2} \mathrm{O}_{2}$ concentration. J. Phys. Chem. C 2010, 114, 6396-6400. 
74. McEachran, M.; Keogh, D.; Pietrobon, B.; Cathcart, N.; Gourevich, I.; Coombs, N.; Kitaev, V. Ultrathin gold nanoframes through surfactant-free templating of faceted pentagonal silver nanoparticles. J. Am. Chem. Soc. 2011, 133, 8066-8069.

75. Liu, T.; Li, D.; Yang, D.; Jiang, M. Fabrication of flower-like silver structures through anisotropic growth. Langmuir 2011, 27, 6211-6217.

76. Kumar, P.S.; Pastoriza-Santos, I.; Rodriguez-Gonzalez, B.; Javier Garcia de Abajo, F.; Liz-Marzan, L.M. High-yield synthesis and optical response of gold nanostars. Nanotechnology 2008, 19, 015606.

77. Mohanty, A.; Garg, N.; Jin, R. A universal approach to the synthesis of noble metal nanodendrites and their catalytic properties. Angew. Chem. Int. Ed. Engl. 2010, 49, 4962-4966.

78. Zhang, H.; Xia, X.; Li, W.; Zeng, J.; Dai, Y.; Yang, D.; Xia, Y. Facile synthesis of five-fold twinned, starfish-like rhodium nanocrystals by eliminating oxidative etching with a chloride-free precursor. Angew. Chem. Int. Ed. 2010, 49, 5296-5300.

79. Mulvihill, M.J.; Ling, X.Y.; Henzie, J.; Yang, P. Anisotropic etching of silver nanoparticles for plasmonic structures capable of single-particle SERS. J. Am. Chem. Soc. 2009, 132, 268-274.

80. Camargo, P.H.; Cobley, C.M.; Rycenga, M.; Xia, Y. Measuring the surface-enhanced Raman scattering enhancement factors of hot spots formed between an individual Ag nanowire and a single Ag nanocube. Nanotechnology 2009, 20, 434020.

81. Le Ru, E.C.; Meyer, M.; Blackie, E.; Etchegoin, P.G. Advanced aspects of electromagnetic SERS enhancement factors at a hot spot. J. Raman. Spectrosc. 2008, 39, 1127-1134.

82. McLellan, J.M.; Li, Z.Y.; Siekkinen, A.R.; Xia, Y.N. The SERS activity of a supported ag nanocube strongly depends on its orientation relative to laser polarization. Nano Lett. 2007, 7, 1013-1017.

83. Olk, P.; Renger, J.; Hartling, T.; Wenzel, M.T.; Eng, L.M. Two particle enhanced nano Raman microscopy and spectroscopy. Nano Lett. 2007, 7, 1736-1740.

84. Talley, C.E.; Jackson, J.B.; Oubre, C.; Grady, N.K.; Hollars, C.W.; Lane, S.M.; Huser, T.R.; Nordlander, P.; Halas, N.J. Surface-enhanced Raman scattering from individual Au nanoparticles and nanoparticle dimer substrates. Nano Lett. 2005, 5, 1569-1574.

85. Goh, M.S.; Lee, Y.H.; Pedireddy, S.; Phang, I.Y.; Tjiu, W.W.; Tan, J.M.; Ling, X.Y. A chemical route to increase hot spots on silver nanowires for surface-enhanced Raman spectroscopy application. Langmuir 2012, 28, 14441-14449.

86. Gunawidjaja, R.; Peleshanko, S.; Ko, H.; Tsukruk, V.V. Bimetallic nanocobs: Decorating silver nanowires with gold nanoparticles. Adv. Mater. 2008, 20, 1544-1549.

87. Peng, Z.; Hu, H.; Utama, M.I.; Wong, L.M.; Ghosh, K.; Chen, R.; Wang, S.; Shen, Z.; Xiong, Q. Heteroepitaxial decoration of Ag nanoparticles on Si nanowires: a case study on Raman scattering and mapping. Nano Lett. 2010, 10, 3940-3947.

88. Wei, H.; Hao, F.; Huang, Y.Z.; Wang, W.Z.; Nordlander, P.; Xu, H.X. Polarization dependence of surface-enhanced Raman scattering in gold nanoparticle-nanowire systems. Nano Lett. 2008, 8, 2497-2502.

89. Lee, S.J.; Baik, J.M.; Moskovits, M. Polarization-dependent surface-enhanced raman scattering from a silver-nanoparticle-decorated single silver nanowire. Nano Lett. 2008, 8, 3244-3247. 
90. Lu, X.M.; Au, L.; McLellan, J.; Li, Z.Y.; Marquez, M.; Xia, Y.N. Fabrication of cubic nanocages and nanoframes by dealloying $\mathrm{Au} / \mathrm{Ag}$ alloy nanoboxes with an aqueous etchant based on $\mathrm{Fe}\left(\mathrm{NO}_{3}\right)_{3}$ or $\mathrm{NH}_{4} \mathrm{OH}$. Nano Lett. 2007, 7, 1764-1769.

91. Zhu, S.; Du, C.; Fu, Y. Localized surface plasmon resonance-based hybrid Au-Ag nanoparticles for detection of Staphylococcus aureus enterotoxin B. Opt. Mater. 2009, 31, 1608-1613.

92. Zhu, S.; Fu, Y. Hybridization of localized surface plasmon resonance-based Au-Ag nanoparticles. Biomed. Microdev. 2009, 11, 579-583.

93. Tsuji, M.; Nishio, M.; Jiang, P.; Miyamae, N.; Lim, S.; Matsumoto, K.; Ueyama, D.; Tang, X.-L. Role of chloride ions in the formation of Au@Ag core-shell nanocrystal structures by using a microwave-polyol method. Colloids Surf. A: Physicochem. Eng. Asp. 2008, 317, 247-255.

94. Tsuji, M.; Matsuo, R.; Jiang, P.; Miyamae, N.; Ueyama, D.; Nishio, M.; Hikino, S.; Kumagae, H.; Kamarudin, K.S.N.; Tang, X.L. Shape-dependent evolution of Au@ Ag core-shell nanocrystals by PVP-assisted N, N-dimethylformamide reduction. Cryst. Growth Des. 2008, 8, 2528-2536.

95. Messina, E.; D’Urso, L.; Fazio, E.; Satriano, C.; Donato, M.G.; D’Andrea, C.; Maragò, O.M.; Gucciardi, P.G.; Compagnini, G.; Neri, F. Tuning the structural and optical properties of gold/silver nano-alloys prepared by laser ablation in liquids for optical limiting, ultra-sensitive spectroscopy, and optical trapping. J. Quant. Spectrosc. Radiat. 2012, 113, 2490-2498.

96. Xue, C.; Millstone, J.E.; Li, S.; Mirkin, C.A. Plasmon-driven synthesis of triangular core-shell nanoprisms from gold seeds. Angew. Chem. Int. Ed. Engl. 2007, 46, 8436-8439.

97. Yin, Y.; Qiu, T.; Ma, L.; Lang, X.; Zhang, Y.; Huang, G.; Mei, Y.; Schmidt, O.G. Exploring rolled-up $\mathrm{Au}-\mathrm{Ag}$ bimetallic microtubes for surface-enhanced raman scattering sensor. J. Phys. Chem. C 2012, 116, 25504-25508.

98. Fu, Q.; Zhang, D.G.; Yi, M.F.; Wang, X.X.; Chen, Y.K.; Wang, P.; Ming, H. Effect of shell thickness on a $\mathrm{Au}-\mathrm{Ag}$ core-shell nanorods-based plasmonic nano-sensor. J. Opt. 2012, 14, 085001.

99. Ghorbanpour, M.; Falamaki, C. Micro energy dispersive x-ray fluorescence as a powerful complementary technique for the analysis of bimetallic $\mathrm{Au} / \mathrm{Ag} / \mathrm{glass}$ nanolayer composites used in surface plasmon resonance sensors. Appl. Opt. 2012, 51, 7733-7738.

100. Yoo, H.J.; Millstone, J.E.; Li, S.Z.; Jang, J.W.; Wei, W.; Wu, J.S.; Schatz, G.C.; Mirkin, C.A. Core-shell triangular bifrustums. Nano Lett. 2009, 9, 3038-3041.

101. Liu, M.; Guyot-Sionnest, P. Synthesis and optical characterization of Au/Ag core/shell nanorods. J. Phys. Chem. B 2004, 108, 5882-5888.

102. Seo, D.; Yoo, C.I.; Jung, J.; Song, H. Ag-Au-Ag heterometallic nanorods formed through directed anisotropic growth. J. Am. Chem. Soc. 2008, 130, 2940-2941.

103. Cho, E.C.; Camargo, P.H.; Xia, Y. Synthesis and characterization of noble-metal nanostructures containing gold nanorods in the center. Adv. Mater. 2010, 22, 744-748.

104. Sanchez-Iglesias, A.; Carbo-Argibay, E.; Glaria, A.; Rodriguez-Gonzalez, B.; Perez-Juste, J.; Pastoriza-Santos, I.; Liz-Marzan, L.M. Rapid epitaxial growth of Ag on Au nanoparticles: from Au nanorods to core-shell Au@Ag octahedrons. Chemistry 2010, 16, 5558-5563.

105. Tsuji, M.; Ogino, M.; Matsunaga, M.; Miyamae, N.; Matsuo, R.; Nishio, M.; Alam, M.J. Crystal structures and growth mechanisms of icosahedral Au@Ag core-shell and Au/Ag twin nanocrystals 
prepared by PVP-AssistedN,N-Dimethylformamide reduction. Cryst. Growth Des. 2010, 10, 4085-4090.

106. Tsuji, M.; Nakamura, N.; Ogino, M.; Ikedo, K.; Matsunaga, M. Crystal structures and growth mechanisms of octahedral and decahedral Au@Ag core-shell nanocrystals prepared by a two-step reduction method. Cryst. Eng. Comm. 2012, 14, 7639-7647.

107. Fan, F.R.; Liu, D.Y.; Wu, Y.F.; Duan, S.; Xie, Z.X.; Jiang, Z.Y.; Tian, Z.Q. Epitaxial growth of heterogeneous metal nanocrystals: From gold nano-octahedra to palladium and silver nanocubes. J. Am. Chem. Soc. 2008, 130, 6949-6951.

108. Ma, Y.; Li, W.; Cho, E.C.; Li, Z.; Yu, T.; Zeng, J.; Xie, Z.; Xia, Y. Au@ Ag core-shell nanocubes with finely tuned and well-controlled sizes, shell thicknesses, and optical properties. ACS Nano 2010, 4, 6725-6734.

109. Tsuji, M.; Hikino, S.; Tanabe, R.; Matsunaga, M.; Sano, Y. Syntheses of Ag/Cu alloy and Ag/Cu alloy core $\mathrm{Cu}$ shell nanoparticles using a polyol method. Cryst. Eng. Comm. 2010, 12, 3900-3908.

110. Hu, Z.S.; Hung, F.Y.; Chang, S.J.; Huang, B.-R.; Lin, B.-C.; Hsieh, W.-K.; Chen, K.-J. Effect of $\mathrm{Ag}$ film thickness on the crystallization mechanism and photoluminescence properties of $\mathrm{ZnO} / \mathrm{Ag}$ nanoflower arrays. Appl. Surf. Sci. 2012, 258, 8049-8054.

111. Karthikeyan, B.; Murugavelu, M. Nano bimetallic $\mathrm{Ag} / \mathrm{Pt}$ system as efficient opto and electrochemical sensing platform towards adenine. Sens. Actuators B: Chem. 2012, 163, 216-223.

112. Zhang, X.Y.; Zhang, T.; Hu, A.; Song, Y.J.; Duley, W.W. Controllable plasmonic antennas with ultra narrow bandwidth based on silver nano-flags. Appl. Phys. Lett. 2012, 101, 153118.

113. Liaw, J.W.; Cheng, J.-C.; Ma, C.; Zhang, R. Theoretical analysis of plasmon modes of Au-Ag nanocages. J. Phys. Chem. C 2013, 117, 19586-19592.

114. Chen, J.Y.; Wiley, B.; Li, Z.Y.; Campbell, D.; Saeki, F.; Cang, H.; Au, L.; Lee, J.; Li, X.D.; Xia, Y.N. Gold nanocages: Engineering their structure for biomedical applications. Adv. Mater. 2005, 17, 2255-2261.

115. Khlebtsov, B.N.; Khanadeev, V.A.; Tsvetkov, M.Y.; Bagratashvili, V.N.; Khlebtsov, N.G. Surface-enhanced raman scattering substrates based on self-assembled pegylated gold and gold-silver core-shell nanorods. J. Phys. Chem. C 2013, 117, 23162-23171.

116. Costa, J.C.S.; Corio, P.; Camargo, P.H.C. Silver-gold nanotubes containing hot spots on their surface: facile synthesis and surface-enhanced Raman scattering investigations. RSC Adv. 2012, 2 , 9801-9804.

117. Gutes, A.; Maboudian, R.; Carraro, C. Gold-coated silver dendrites as SERS substrates with an improved lifetime. Langmuir 2012, 28, 17846-17850.

118. Kang, T.; Yoo, S.M.; Yoon, I.; Lee, S.; Choo, J.; Lee, S.Y.; Kim, B. Au nanowire-on-film SERRS sensor for ultrasensitive $\mathrm{Hg}^{2+}$ detection. Chemistry 2011, 17, 2211-2214.

119. Duan, J.; Yang, M.; Lai, Y.; Yuan, J.; Zhan, J. A colorimetric and surface-enhanced Raman scattering dual-signal sensor for $\mathrm{Hg}^{2+}$ based on Bismuthiol II-capped gold nanoparticles. Anal. Chim. Acta 2012, 723, 88-93.

120. Kang, T.; Yoo, S.M.; Kang, M.; Lee, H.; Kim, H.; Lee, S.Y.; Kim, B. Single-step multiplex detection of toxic metal ions by $\mathrm{Au}$ nanowires-on-chip sensor using reporter elimination. Lab. Chip 2012, 12, 3077-3081. 
121. Du, Y.; Liu, R.; Liu, B.; Wang, S.; Han, M.Y.; Zhang, Z. Surface-enhanced Raman scattering chip for femtomolar detection of mercuric ion (II) by ligand exchange. Anal. Chem. 2013, 85, 3160-3165.

122. Gui, R.; Jin, H. Aqueous synthesis of human serum albumin-stabilized fluorescent $\mathrm{Au} / \mathrm{Ag}$ core/shell nanocrystals for highly sensitive and selective sensing of copper(II). Analyst 2013, 138, 7197-7205.

123. Panfilova, E.; Shirokov, A.; Khlebtsov, B.; Matora, L.; Khlebtsov, N. Multiplexed dot immunoassay using Ag nanocubes, Au/Ag alloy nanoparticles, and Au/Ag nanocages. Nano Res. 2012, 5 , 124-134.

124. Liu, B.; Han, G.; Zhang, Z.; Liu, R.; Jiang, C.; Wang, S.; Han, M.Y. Shell thickness-dependent Raman enhancement for rapid identification and detection of pesticide residues at fruit peels. Anal. Chem. 2012, 84, 255-261.

125. Zheng, X.; Chen, Y.; Chen, Y.; Bi, N.; Qi, H.; Qin, M.; Song, D.; Zhang, H.; Tian, Y. High performance $\mathrm{Au} / \mathrm{Ag}$ core/shell bipyramids for determination of thiram based on surface-enhanced Raman scattering. J. Raman. Spectrosc. 2012, 43, 1374-1380.

126. Trang, N.T.T.; Thuy, T.T.; Higashimine, K.; Mott, D.M.; Maenosono, S. Magnetic-plasmonic FePt@Ag core-shell nanoparticles and their magnetic and SERS properties. Plasmonics 2013, 8, $1177-1184$.

127. Tian, Z.Q.; Ren, B.; Li, J.F.; Yang, Z.L. Expanding generality of surface-enhanced Raman spectroscopy with borrowing SERS activity strategy. Chem. Commun. 2007, 3514-3534.

(C) 2014 by the authors; licensee MDPI, Basel, Switzerland. This article is an open access article distributed under the terms and conditions of the Creative Commons Attribution license (http://creativecommons.org/licenses/by/3.0/). 